Iranian Journal of Breast Diseases. 2021; 13(4):8-22.
Original Article

\section{Comparing the Effect of In-Person and Virtual Lymphedema Self-management Education on Quality of Life of Women with Breast Cancer: A Randomized Clinical Trial}

\author{
Kheirkhah $\mathbf{M}^{1}$, Haghighat $\mathrm{S}^{2^{*}}$, Omidi $\mathrm{Z}^{1^{*}}$ \\ ${ }^{1}$ Nursing Care Research Center (NCRC), School of Nursing and Midwifery, \\ Iran University of Medical Sciences, Tehran, Iran \\ 2 Integrative Oncology and Quality of Life Department, Breast Cancer \\ Research Center, Motamed Cancer Institute, ACECR, Tehran, Iran
}

Receive: $2 / 6 / 2020$

Accepted: 11/8/2020

"Corresponding Author: sha_haghighat@yahoo.com Z.omidii67@gmail.com

Ethics Approval: IR.IUMS.REC1395.9411173002

\begin{abstract}
Introduction: Breast cancer-related lymphedema is a chronic swelling accompanied by physical discomfort and prolonged treatment negatively affecting patients' quality of life (QoL). Self-management is a vital phase in managing the results of treatment. So, the study aims to compare the effect of in-person and virtual self-management education on women's quality of life.

Methods: This was a randomized clinical trial conducted on 70 women with breast cancer-related lymphedema in the last one year, attending to Seyed_Khandan rehabilitation center in Tehran. Sampling was done by random allocation method in blocks of 2 with 35 subjects in each group. All subjects received routine lymphedema treatment. The in-person and virtual groups received the education at the clinic and the Telegram messenger, respectively. QoL was assessed using the Persian version of EORTC QLQ-C30 and QLQBR23 questionnaires on before, immediately, and three months after the intervention.
\end{abstract}

Results: The mean age of the individuals was 51.42 \pm 9.71 . Most subjects were married, had a diploma or higher, and the mean duration of lymphedema was 6.88 months. At the end of the study compared to the beginning of the study, physical, role, emotional and social functions decreased significantly in the virtual group compared with the in-person group. In this way, the status of the mentioned variables in the in-person group was better than the virtual one $(\mathrm{P}=0.006, \mathrm{P}=0.026, \mathrm{P}=0.014, \mathrm{P}=0.023$, respectively). Three months after the intervention, median scores on global health $(\mathrm{P}=0.21)$, physical functioning $(\mathrm{P}=0.004)$, role functioning $(\mathrm{P}=0.009)$, emotional functioning $(\mathrm{P}<0.001)$, social functioning $(\mathrm{P}=0.048)$ were still significantly greater for the in-person group. Also, the in-person group had a greater reduction in the median scores of systemic therapy side effects $(\mathrm{P}=0.002)$ and arm symptoms $(\mathrm{P}=0.45)$ compare with the virtual group.

Conclusion: Self-management education led to improved quality of life, and in the comparison between the two methods, in-person method was more effective than virtual method. However, further studies are needed to investigate the efficacy and cost-effectiveness of both methods in educating patients with lymphedema.

Keywords: Self-management, Lymphedema, Quality of Life, Breast Cancer 


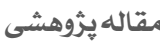

مقايسه تأثير آموزش خودمليريتى لنف ادم به دو شيوه حضورى و

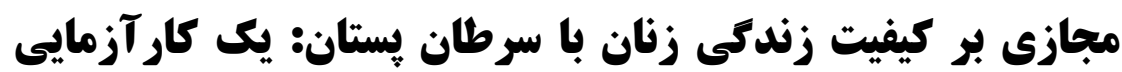

بالينى تصادفى

\author{
معصومه خيرخواه'، شهير حقيقت r"، زهرا اميدى"'
}

' مركز مراقبتهاى يرستارى، دانشكده يرستارى و مامايى دانشعاه علوم يزشكى خدمات بهداشتى درمانى

يران، تهران، ايران

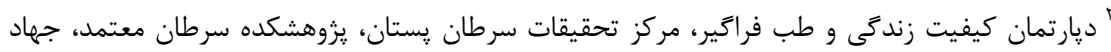

دانشخاهى، تهران، ايران
فصلنامه بيمارى هاى يستان ايران

$1 T 99 ! \operatorname{Ir}(\varepsilon): r r-9$

\section{جكيده}

مقدمه: لنف ادم مرتبط با سرطان يستان تورمى مزمن با عوارض جسمانى و درمان طولانى مدت است

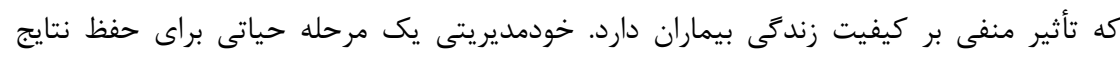

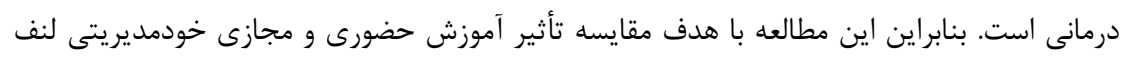
ادم بر كيفيت زندگى زنان انجام گرديد.

روش بررسى: يروهش حاضر يك كارآزمايى بالينى بر روى • V بيمار مبتلا به لنف ادم ناشى از

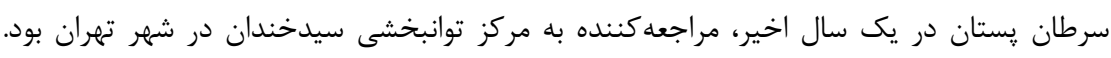

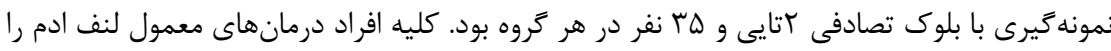

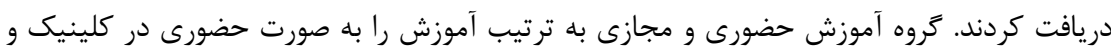

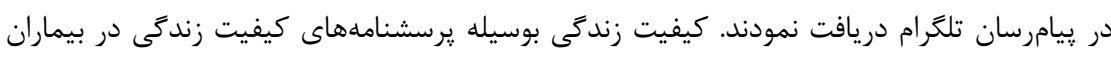

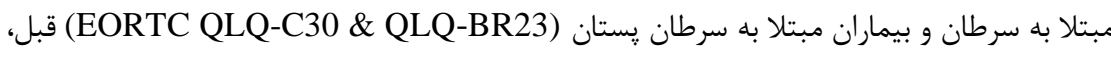

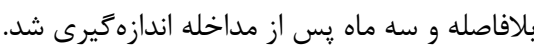

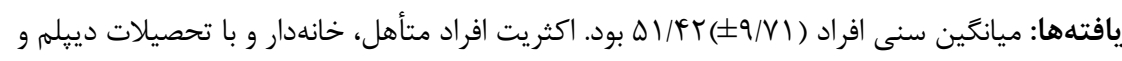

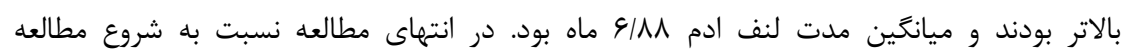

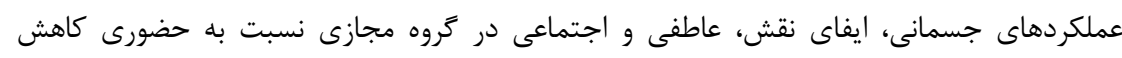

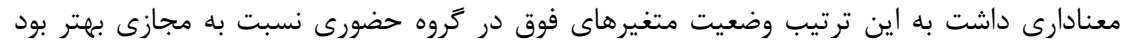

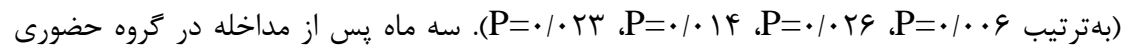

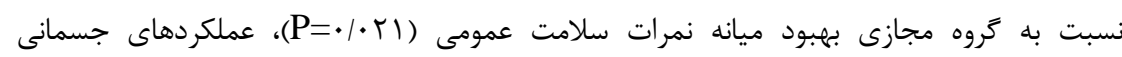

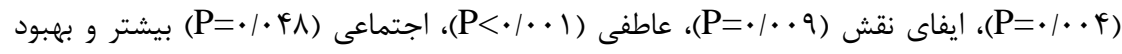

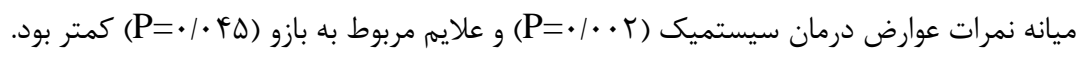

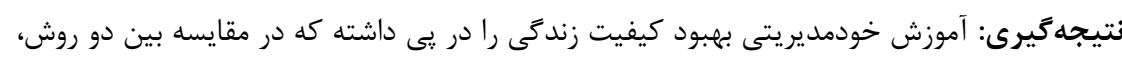

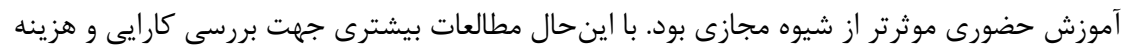
اثربخشى هر دو شيوه در آموزش مبتلايان به لنف ادم نياز است آدال وازههاى كليدى: خودمديريتى، لنف ادم، كيفيت زندگى، سرطان پستان

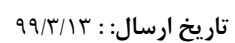

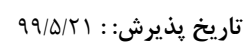

"نويسنده مسئول:

sha_haghighat@yahoo.com Z.omidii67@gmail.com 
است (r، أ). خودمديريتى اغلب بلهورت حضورى آموزش

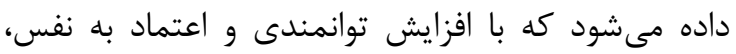
تسهيل روابط مثبت و حمايت اجتماعى همراه است (• (1).

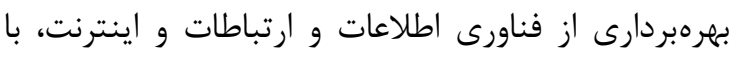

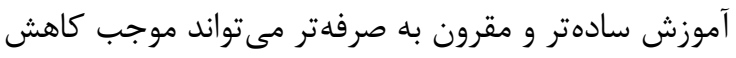
استرس بيمار، بهبود روند درمان، توانمندسازى افراد در در درد

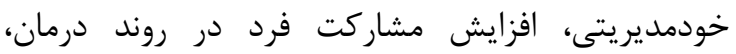

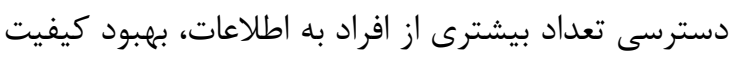

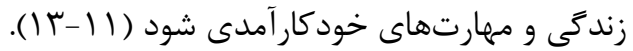

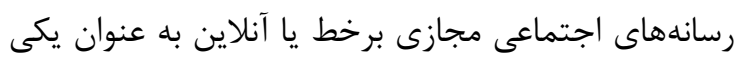

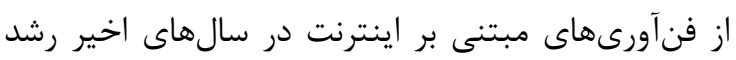

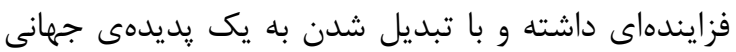
قابليت حمايت اجتماعى، توانمندسازى، اشتراك تذارى

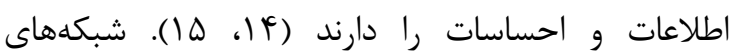

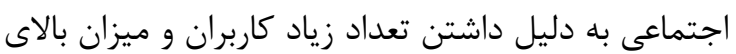

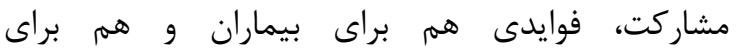

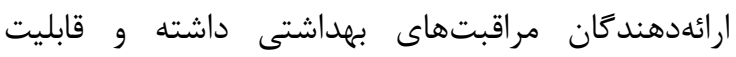
فراوانى جهت كاربرد در حوزه سلامت دارند. اين شبكدهان إنها

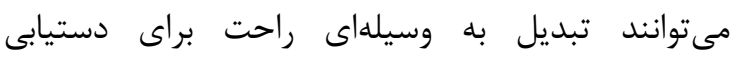
بازماندكان سرطان به اطلاعات مورد نياز خود در رابطه با بالئ

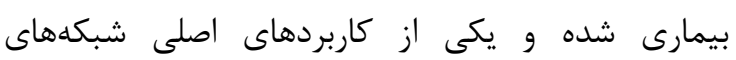

اجتماعى در حوزه سلامت آموزش بيماران است (بارئ (1).

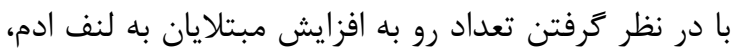

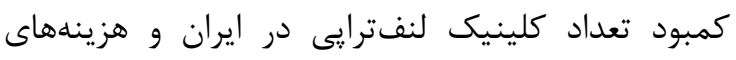
آموزش حضورى از جمله هزينههاى يرسنلى، هزينه هاى تعداى

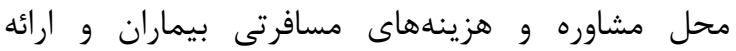
دهندكان خدمات بهداشتى، استفاده از امكانات فضاى

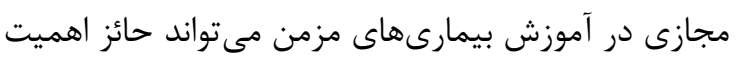

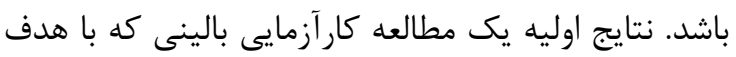

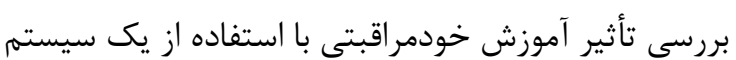

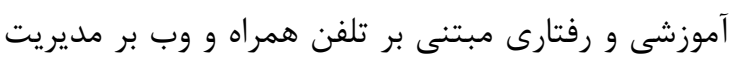

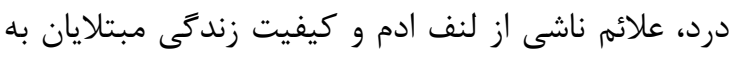

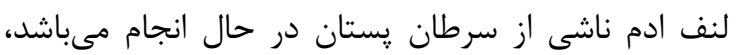

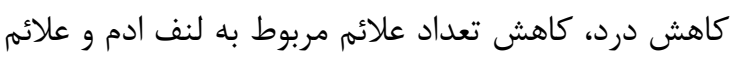

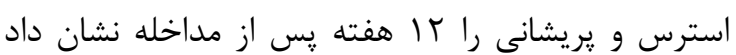

از آنجا كه كيفيت زندگى بازماندكان سرطان يستان ممكن

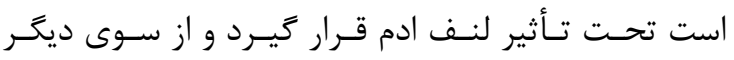

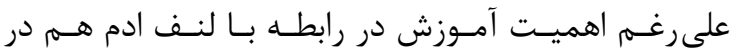

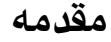

با پِيشرفت در تشخيص و درمان زودهنگام سرطان پستان

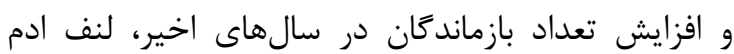

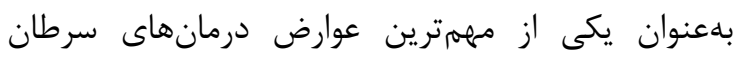

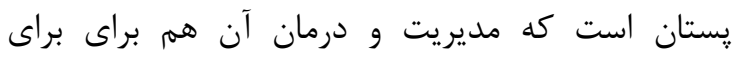

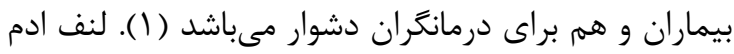

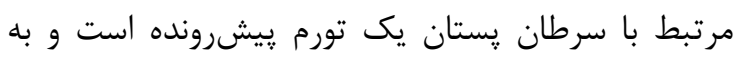

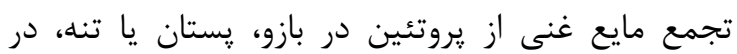

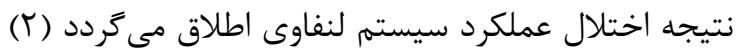

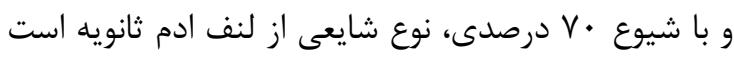

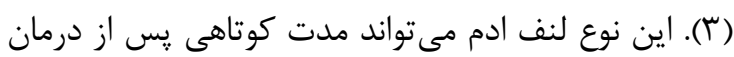

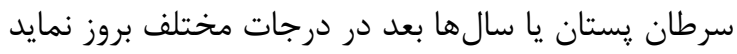

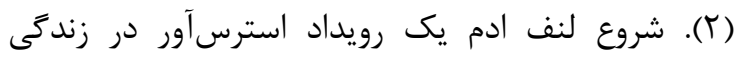

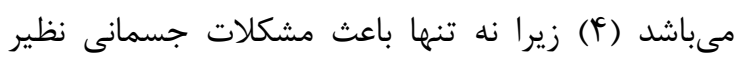

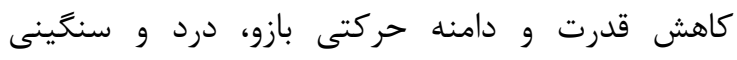

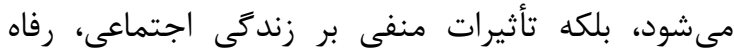

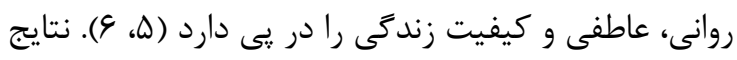

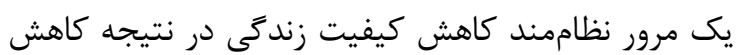

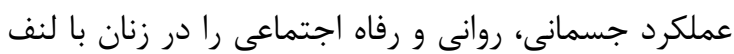

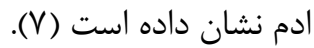
يس از يك بار ايجاد لنف ادم نياز به خودمديريتى در طول

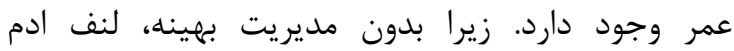

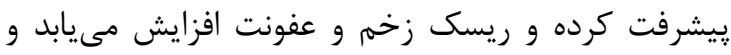
تأثيرات

منفى بر اقتصاد فردى (به دليل افزايش هزينههاى درمان)،

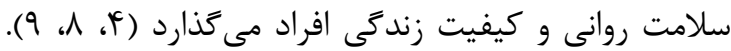
خودمديريتى فاز دوم يا فاز نكهدارنده درمان استاندارد لنف ادم يا CDT است كه هدف آن حفظ نتايج درمان در سراسر عمر مىباشد (9). عليرغم اهميت خودمديرتى

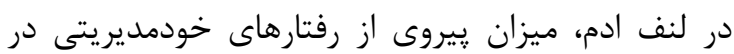

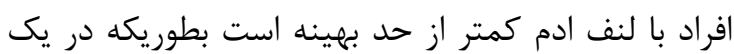

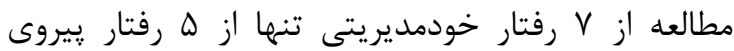

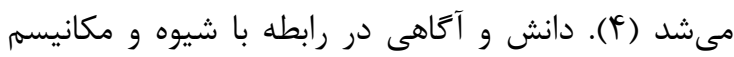

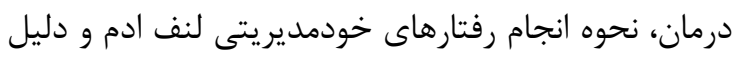

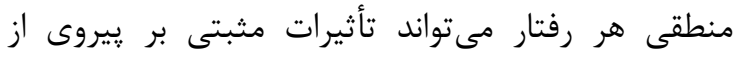
رفتارهاى خودمديريتى داشته باشد. بنابراين آموزش يك تئي

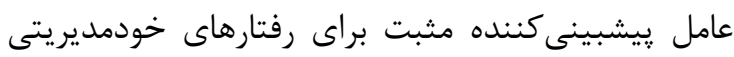

\footnotetext{
${ }^{1}$ Complete Decongestive Therapy
} 
لنف ادم و لوح فشردهى ورزشهاى بازتوانى قرار مى كرفتند. اين درمان در دو فاز حاد و نتخهدارنده ارائه

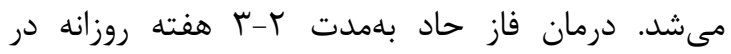

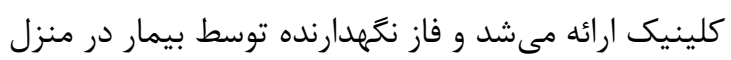

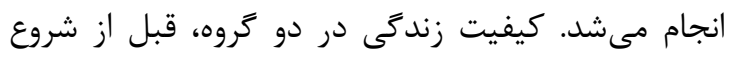

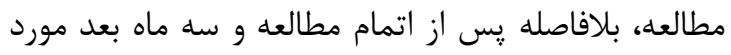

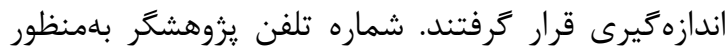

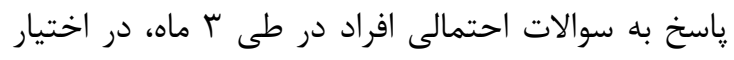

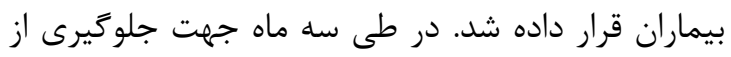

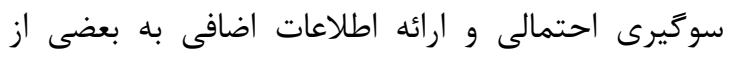

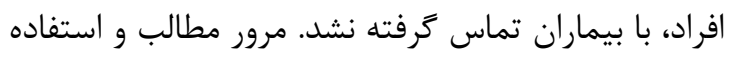

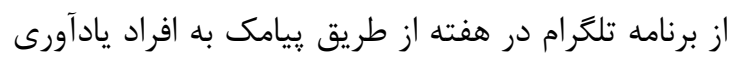

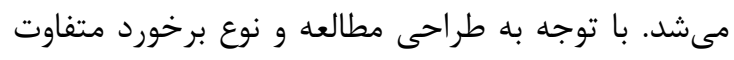

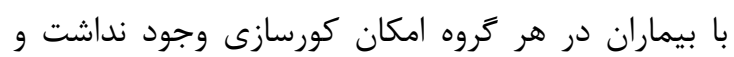

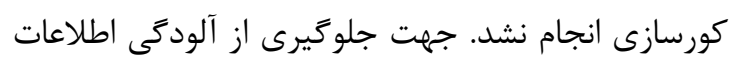

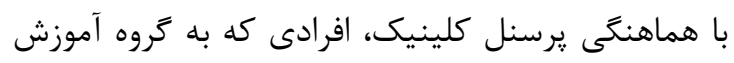

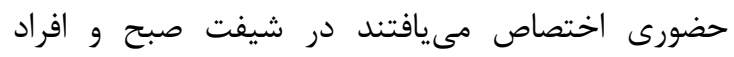

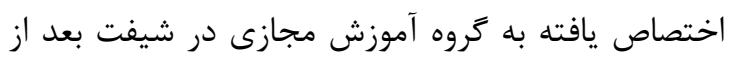

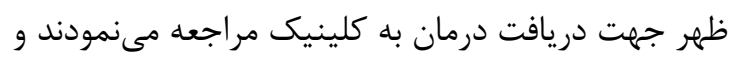

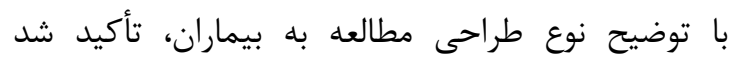

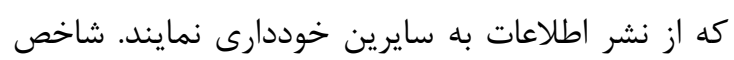

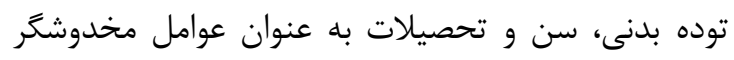
اندازمخيرى شدند. محتواى آموزشى پِ پـ از مطالعات كتابخانهاى و تأييد سه

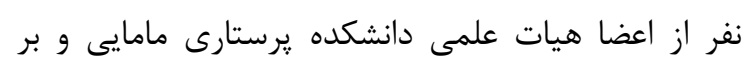

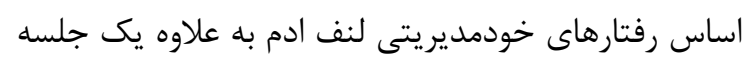
راهكارهاى مديريت استرس طراحى شد. در خدر جلسات

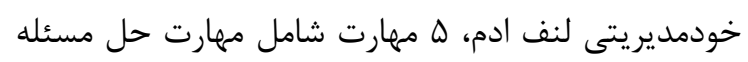

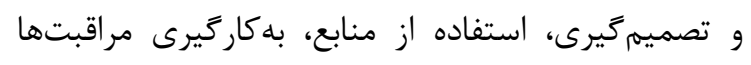
متناسب با وضعيت شخصى، همكارى با تيم درمانى و به إنها

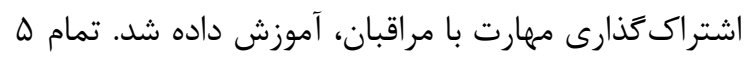

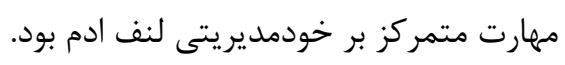

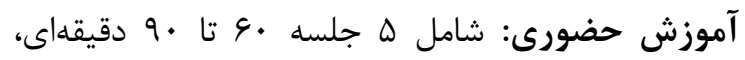

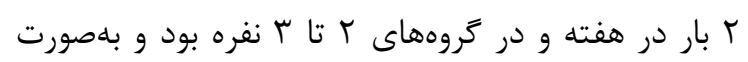

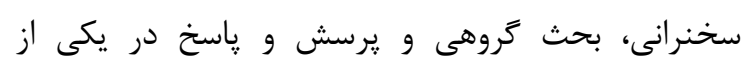

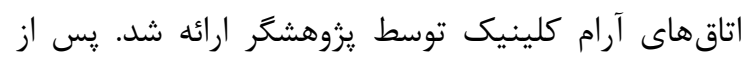

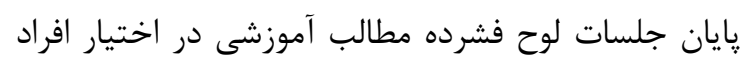

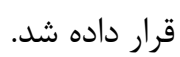

كشورهاى توسعه يافته و هم در كشورهاى در حال توسعه،

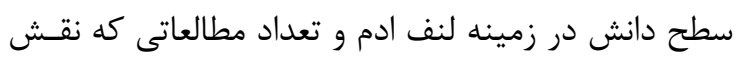

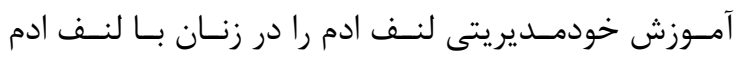
بررسى نمايند كم مى باشد، اين مطالعه بر آن شد تـا تـأثير

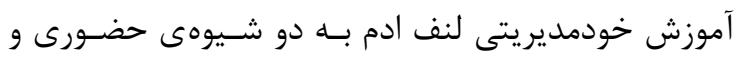

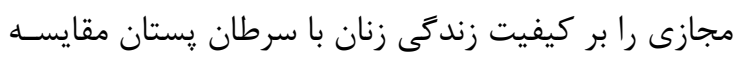

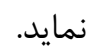

\section{مواد و روشها}

اين يزوهش يك مطالعه كارآزمايى بالينى تصادفى بود كه

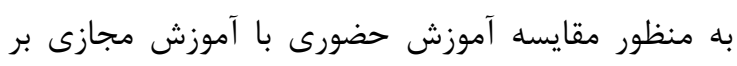

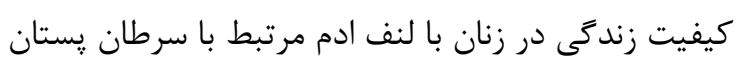

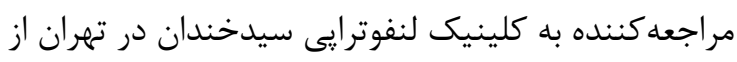

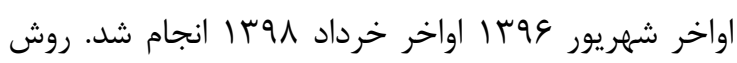
نمونهَيرى مستمر و تخصيص نمونهها بلهصورت بلوى

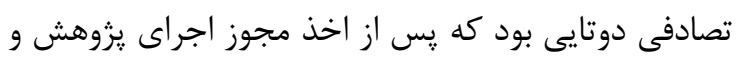

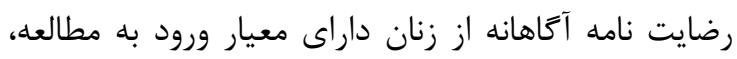
انجام كرديد. مطالعه توسط كميته اخلاق دانشخاه علوم يزشكى ايران (IR.IUMS.REC1395.9411173002)

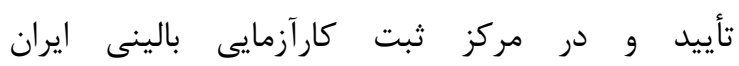
(IRCT2017052834176N1) معيارهاى ورود به مطالعه داشتن سابقه سرطان يستان

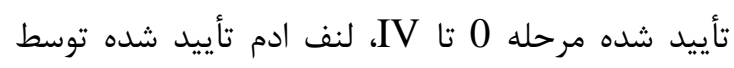

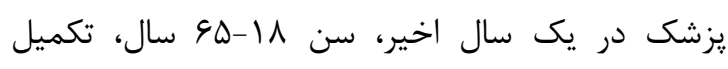

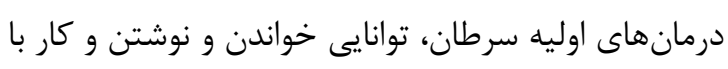

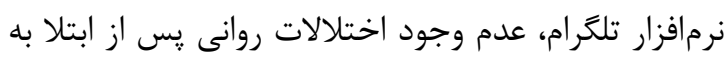

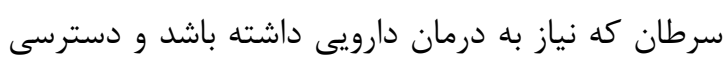

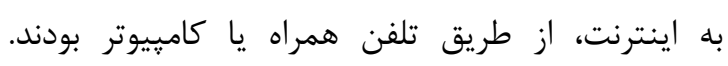

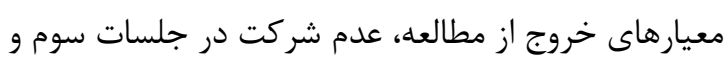

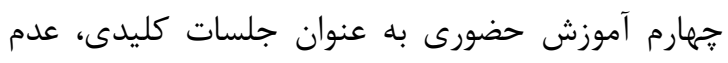

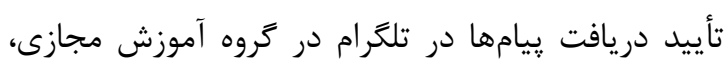

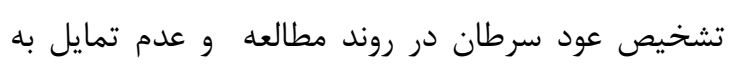
ادامه مداخله بودند. بيماران علاقهمند و داراى معيار ورود به مطالعه توسط بودن

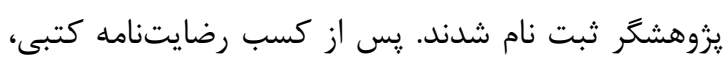

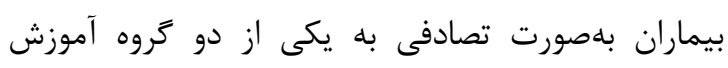
حضورى يا آموزش حضورى تخصيص داده شدند. كليه

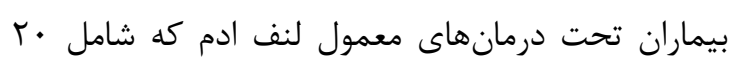

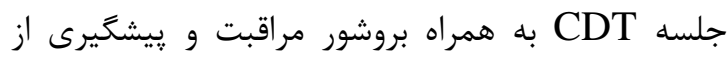


نمره بالاتر در حيطه عملكردى و سلامت عمومى نمانى نشاندهنده عملكرد و وضعيت بهتر و نمره بالاتر در حيطه علائم نشاندهنده حضور علائم بيشتر و وضعيت بدتر است.

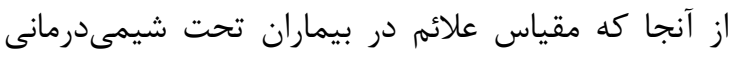
يا دوره يس از شيمىدرمانى جهت سنجش على علائم اختصاصىتر است و بيماران تحت مطالعه ما مبتلايان به داريه لنف ادم هستند كليه سوالات توسط افراد مطالعه پِاسخ داده شد اما سوالات مربوط به علائم در اين يرسشنامه در تجزيه و تحليل دادهها وارد نشدند. نسخه فارسى يرسشنامه تكميلى ويزه اندازهكيرى كيفيت زندكى در بيماران مبتلا به سرطان

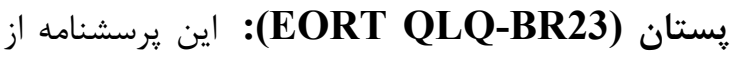

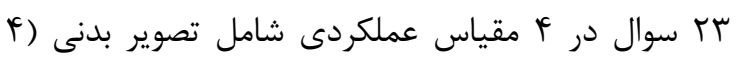
سوال)، عملكرد جنسى (זسوال)، لذت جنسى (اسوال)،

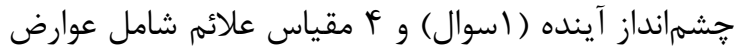

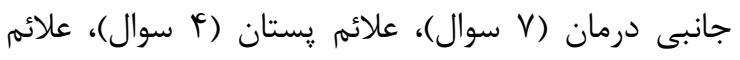
بازو (ب سوال) و ناراحتى از ريزش مو (ان سوال)، تشكيل

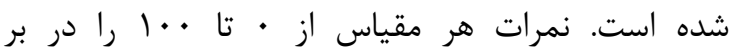

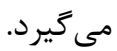
يرسشنامه به صورت ليكرت أتايى طراحى شده است. نمره بالاتر در حيطه عملكردى نشاندهنده عملكرد و وضعيت بهتر و نمره بالاتر در حيطه علائم نشاندهنده

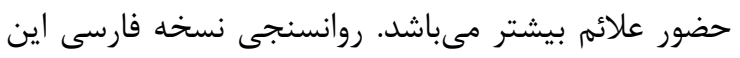

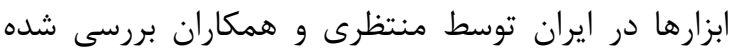

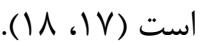
حجم نمونه با در نظر كرفتن

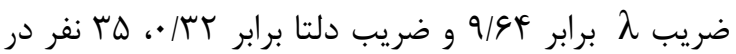
هر بازو انتخاب شد. نمونه تصادفىسازى بر اساس بلوك تصادفى دوتايى انجام شد. نمونهها بر اساس ليست تصادفى شده وارد مطالعه شدند.

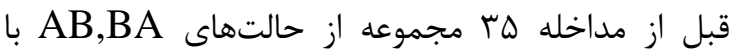
شمارهاى 1 تا هـ توسط متخصص آمار با استفاده از نرم افزار اكسل به تصادف تهيه شد. هر دو بيمارى كه وارد آنار مطالعه مىشدند مىبايست در يكى از مجموعهها قرار

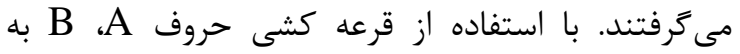

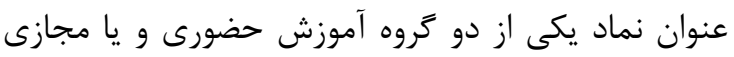
انتخاب شد. بر اساس حروف مشخص شده آدران افراد وارد هريك از دو گروه مطالعه مى شدند (شكل ( ).
آموزش مجازى: آموزش مجازى از طريق پيامرسان

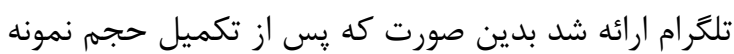
تخصيص داده شده به تروه آموزش مجازى، يك كانال در

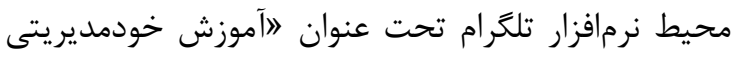
لنف ادمه ايجاد شد و سيس همه افراد توسط يزوهشكر

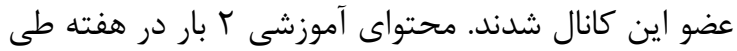

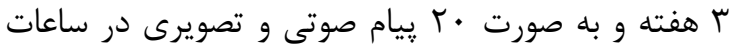

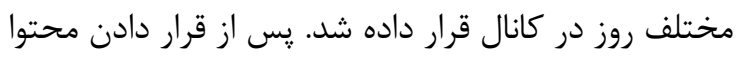

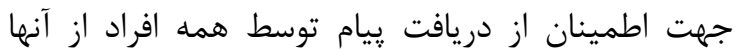
خواسته شد كه هريك در صورت دريافت محتوا به ادمين كانال اطلاع داده يا نظر خود را اعلام نمايند.

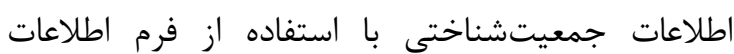
جمعيتشناختى محقق ساخته قبل از مداخله و با استفاده از خودكزارشدهى و يرونده يزشكى بيماران تكميل كرديد.

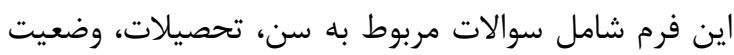

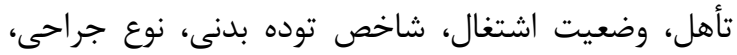

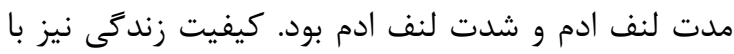

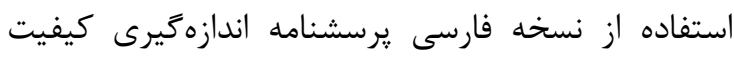
زندگى در بيماران مبتلا به سرطان متعلق به سازمان ارويايى تحقيق و درمان سرطان (EORTC QLQ-C30) و ورسشنامه تكميلى ويزه اندازهخيرى كيفيت زندانى

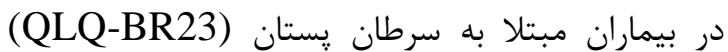

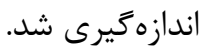

نسخه فارسى يرسشنامه اندازهكيرى كيفيت زندكى در بيماران مبتلا به سرطان -EORTC QLQ):

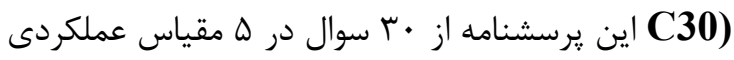

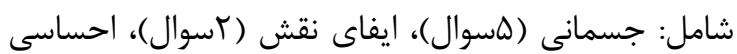
(זسوال)، شناختى (זاسوال)، اجتماعى (r سوال)، 9

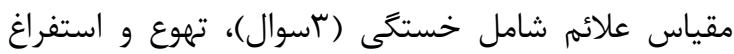

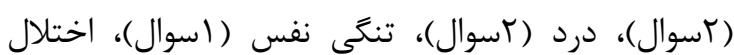
خواب ( اسوال)، كاهش اشتها (اسوال)، يبوست (اسوال)،

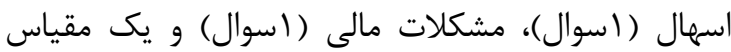

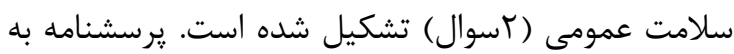
صورت ليكرت ثاتايى طراحى شده است بجز در حيطه

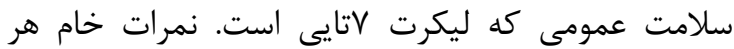

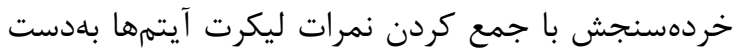

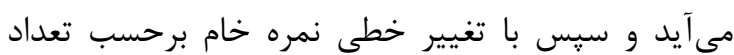

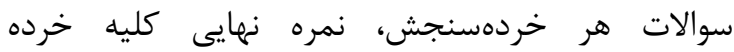

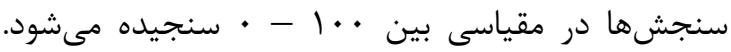




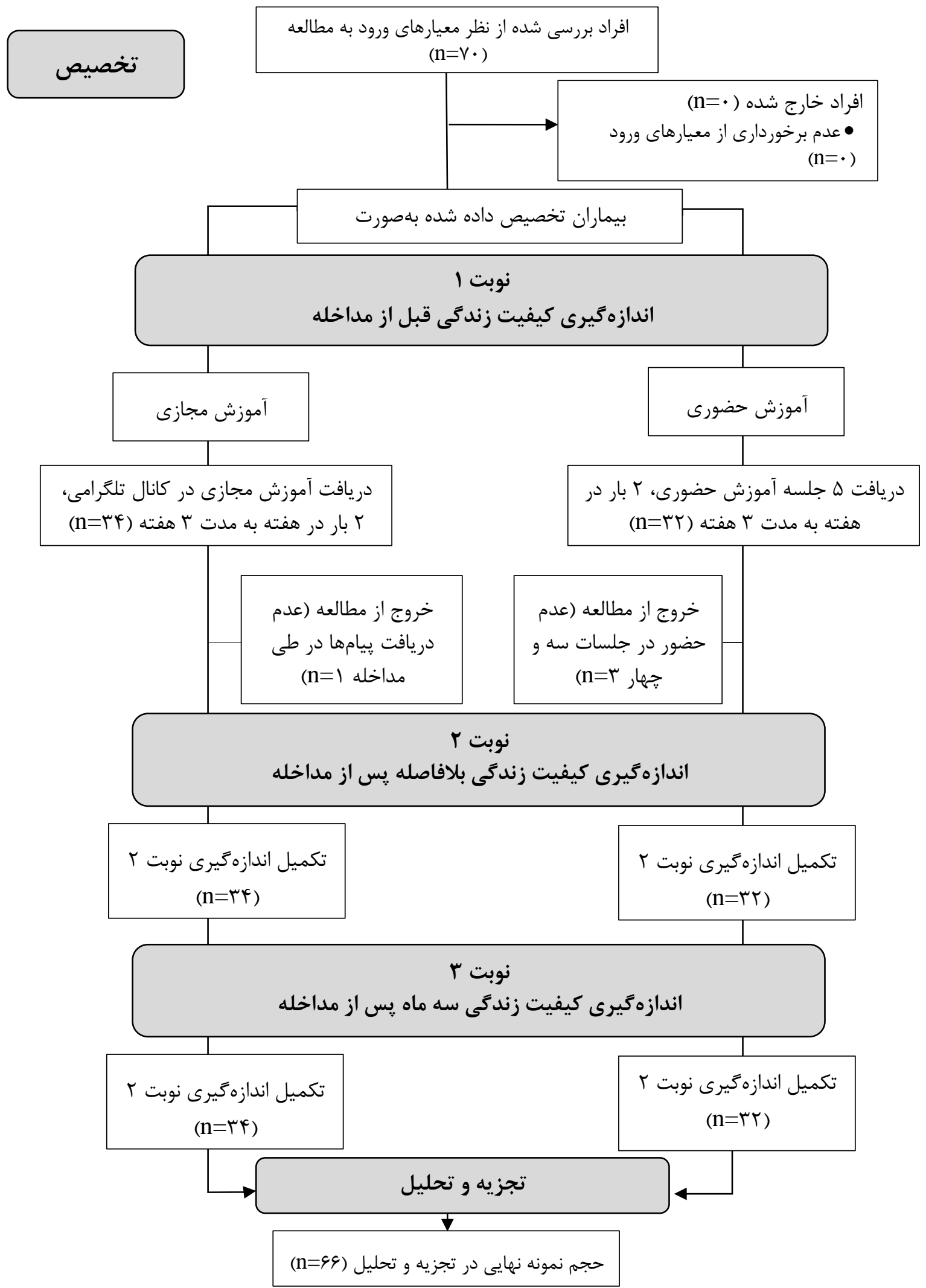

شكل ا: دياكرام كونزورت / بررسى، ورود، تصادفىسازى، پييگيرى و تجزيه و تحليل 
بر اساس آزمون فريدمن تغييرات نمرات حيطههاى

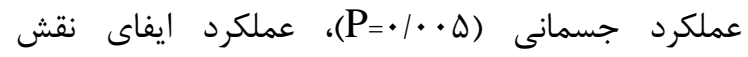

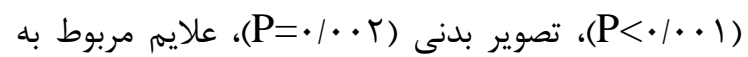

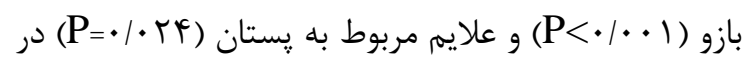

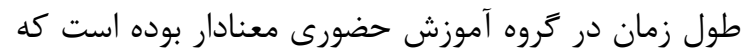
نتايج آزمون تعقيبى نشان داد كه مقدار P بين بلافاصله

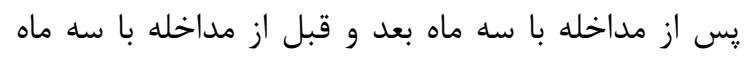

$$
\text { بعد معنادار مىباشد. تغيير }
$$

نمرات در هيج يك از حيطههاى كيفيت زندگى در گروها

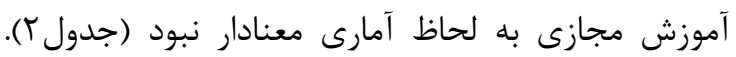

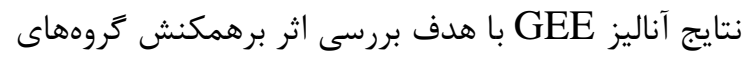
مطالعه و كذشت زمان بر خرده سنجشهاى كيفيت زندگى در جدول ب ززارش شده است.

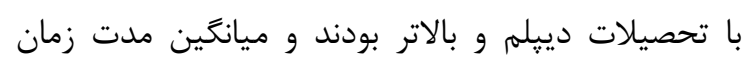
لنف ادم \&1/ جمعيتى تفاوت معنادار آمارى وجود نداشت.

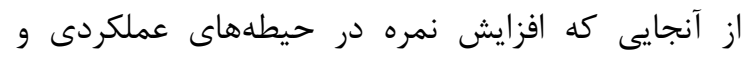
سلامت عمومى يرسشنامه كيفيت زندكى همسو با بهبود كيفيت زندگى بوده و در حيطههاى علائم افزايش نمره با

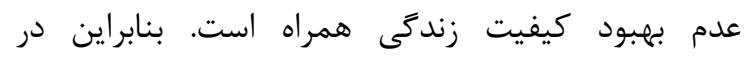
حيطههاى عملكردى $\beta$ مثبت همسو با افزايش كيفيت

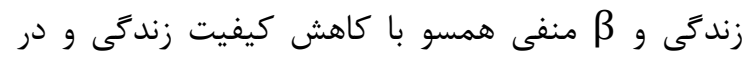
حيطههاى علائم $\beta$ مثبت همسو با كاهش كيفيت زندكى و بتا منفى همسو با افزايش كيفيت زندگى است. بر اين

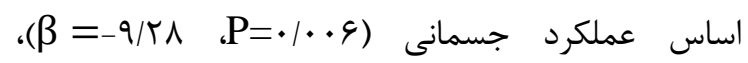

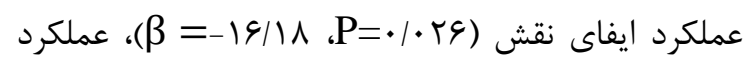

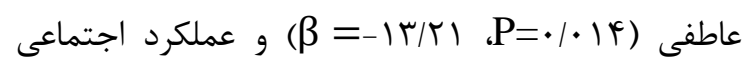

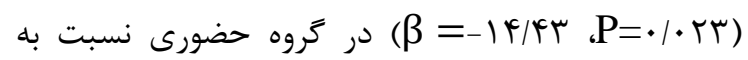
گروه مجازى در انتهاى مطالعه نسبت به شروع مطالعه به

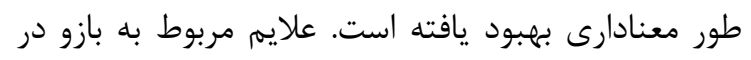

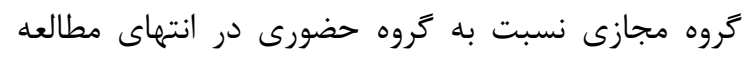

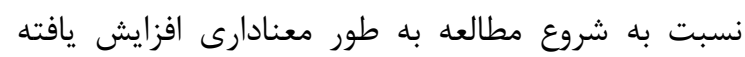

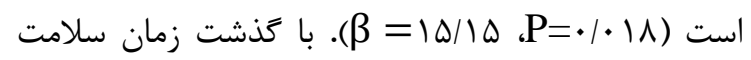
عمومى در زروه مجازى نسبت به حضورى در بلافاصله

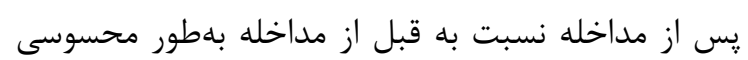

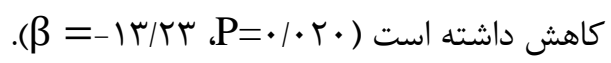

تجزيه و تحليل آمارى دادهها با استفاده از نرمافزار

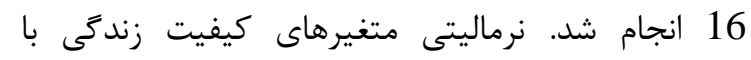

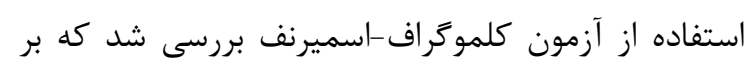

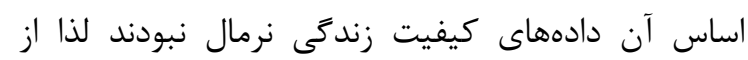

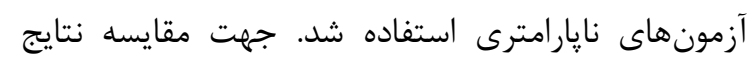

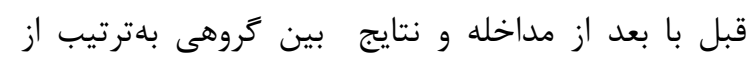

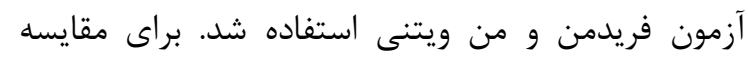

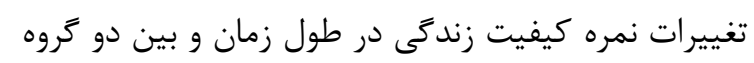

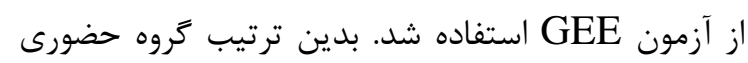

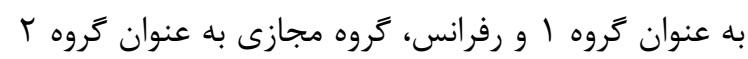

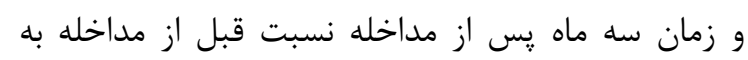

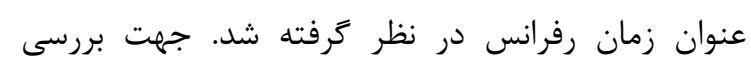
تفاوت بين متغيرهاى جمعيت شناختى و بالينى از آزمون

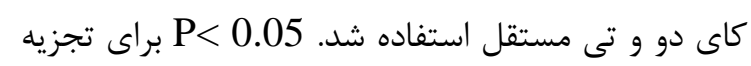
و تحليلها از لحاظ آمارى معنادار بود.

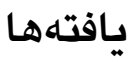

در اين مطالعه، ب نفر در گروه آموزش حضورى (به دليل

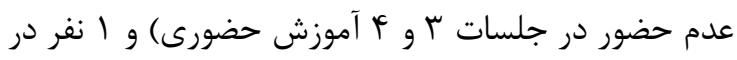

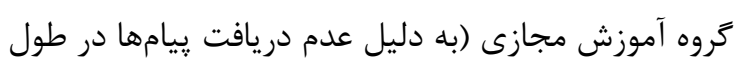

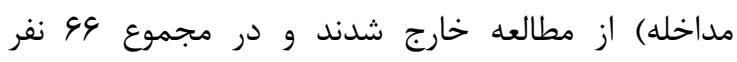

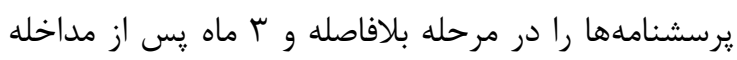

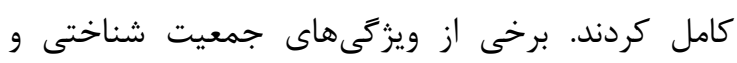

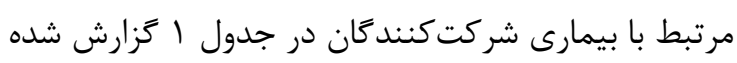

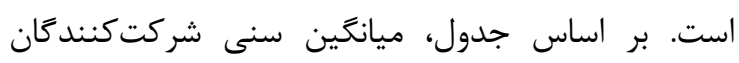

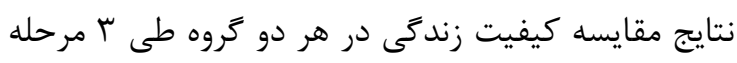

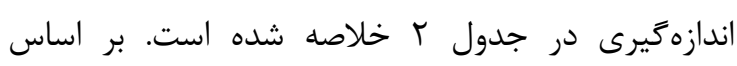

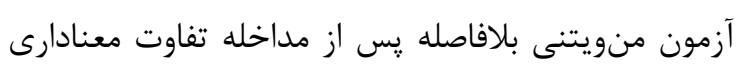

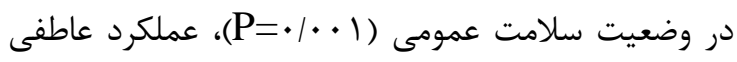

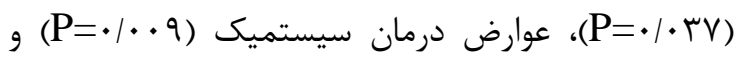

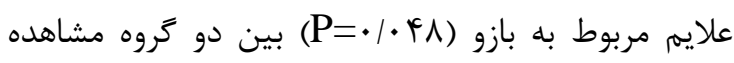

سه ماه يس از مداخله در حيطههاى سلامت عمومى،

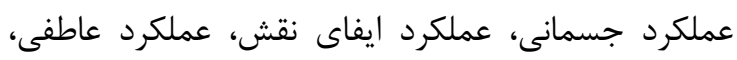

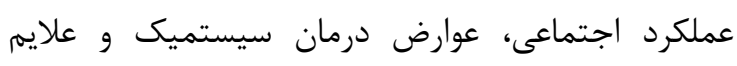

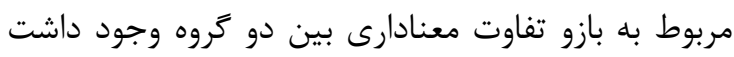

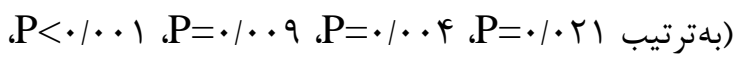

$$
\text { . } \mathrm{P}=\cdot / \cdot r \Delta, \mathrm{P}=\cdot / \cdot r \mathrm{r}, \mathrm{P}=\cdot / \cdot r \wedge
$$


جدول ا: مقايسه متغيرهاى جمعيتى در زنان با لنف ادم در كروههاى مورد مطالعه

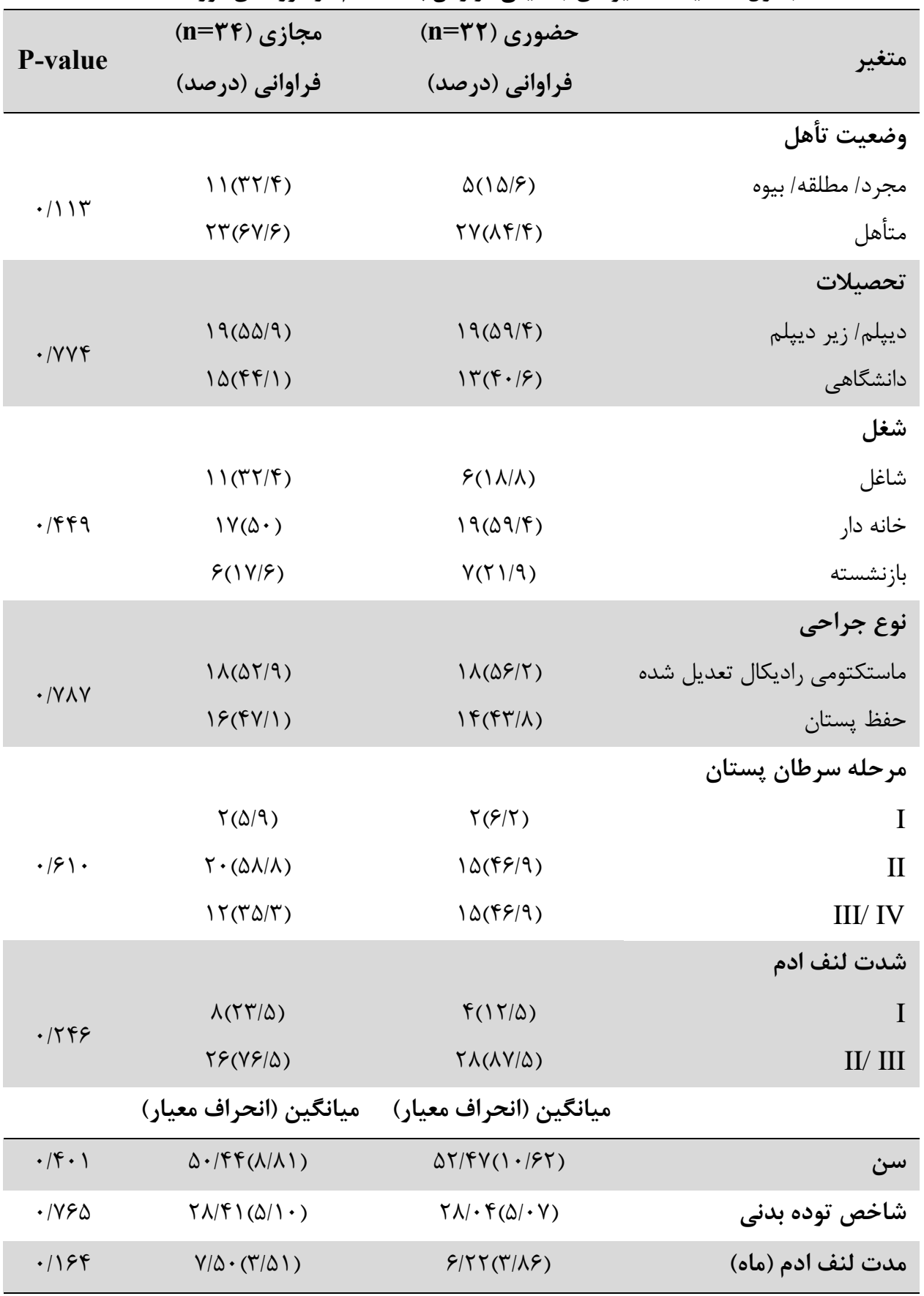


جدول r: مقايسه كيفيت زندكى بين كروهها طى سه مرحله اندازهخيرى

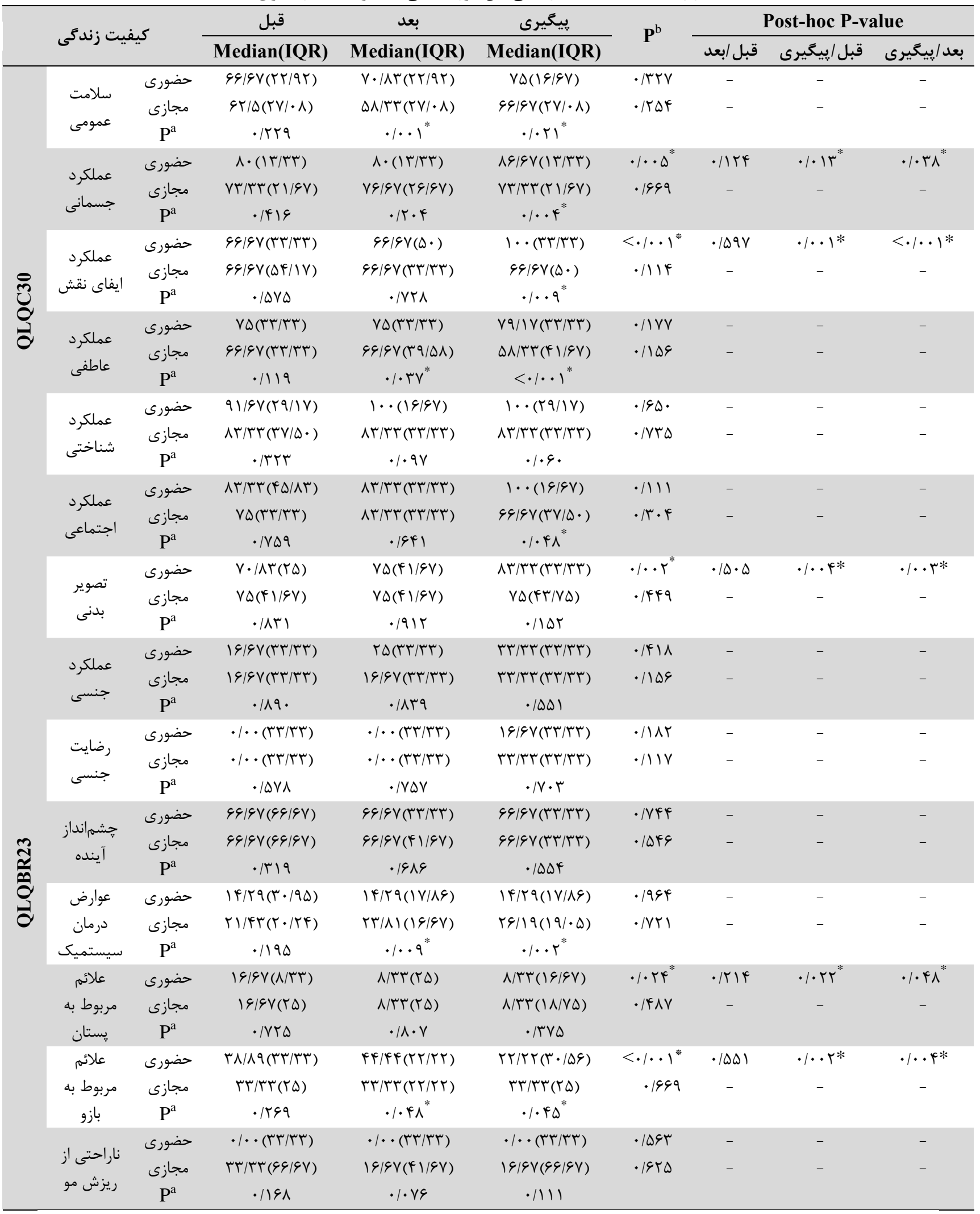

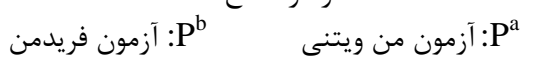

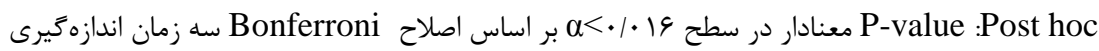




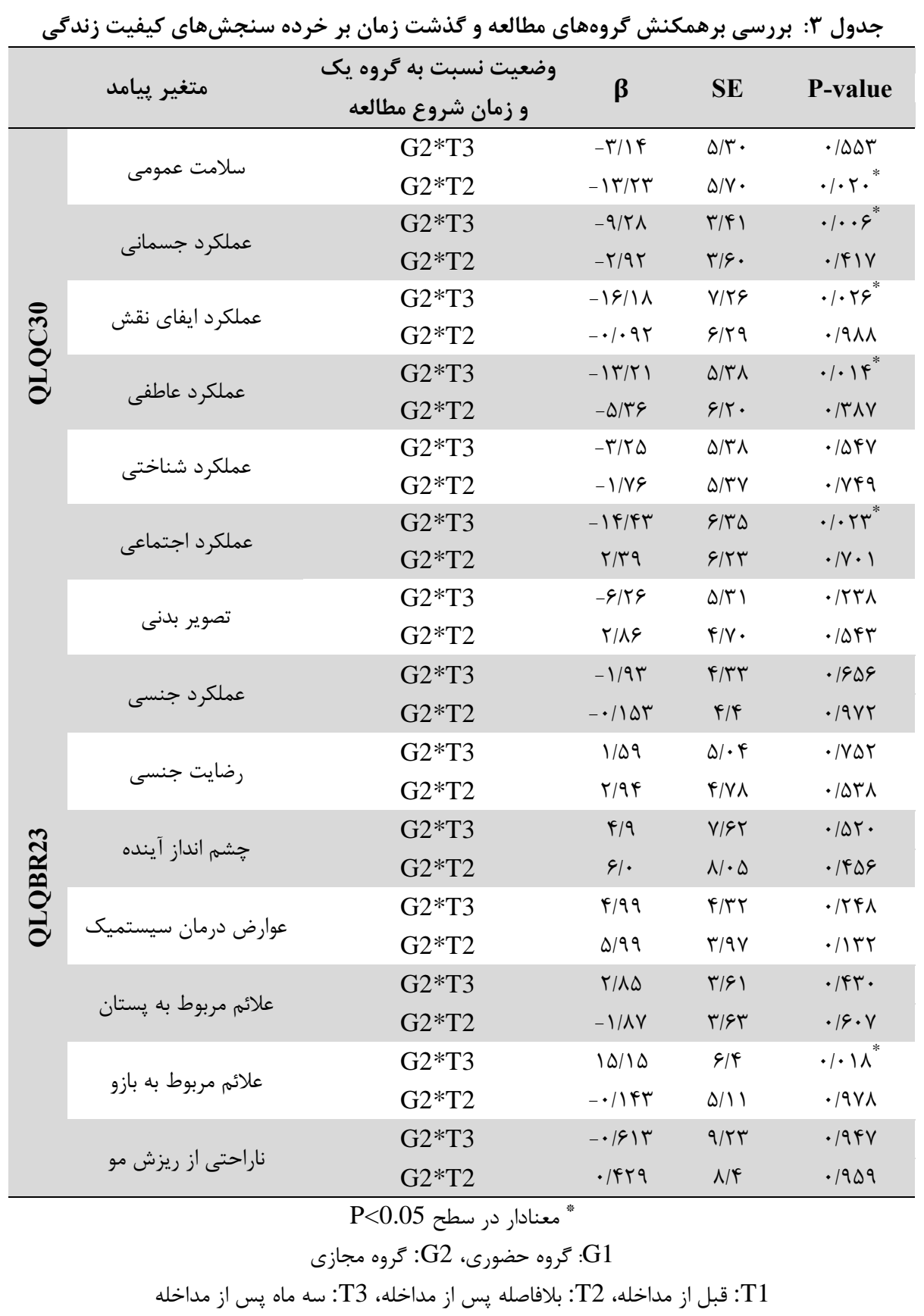

اجتماعى، عوارض درمان سيستميك و علائم مربوط به بازو

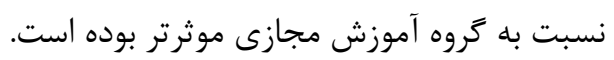

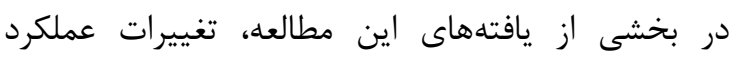
جسمانى دركروه مجازى نسبت به كروه حضورى درى در خاتمه

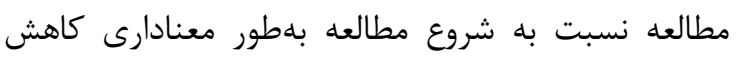

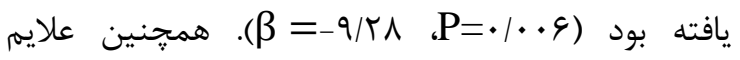

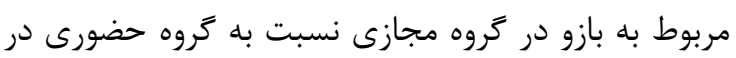

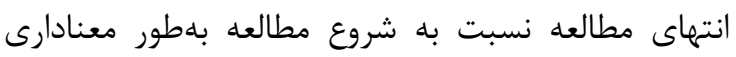

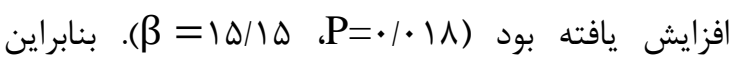
آموزش حضورى بر بهبود كيفيت زندكى موثرتر بوده است.

\section{بحث} اين مطالعه يكى از اولين مطالعات انجام شده در زمينه

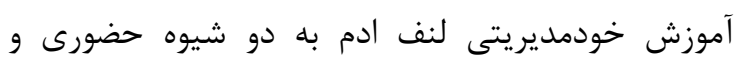

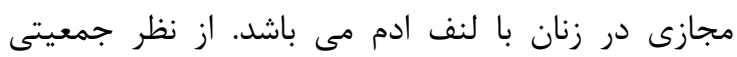

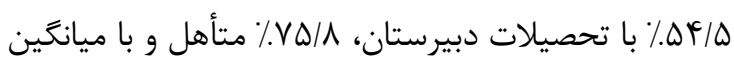

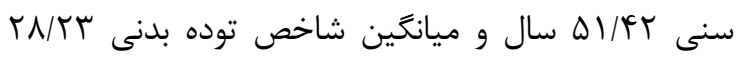

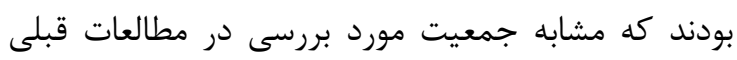

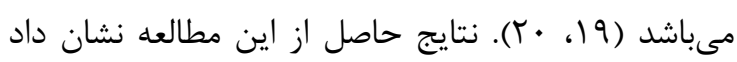

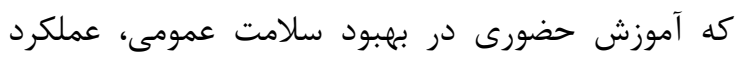
جسمانى، عملكرد ايفاى نقش، عملكرد درد عاطفى، عملكرد سلامت عمودي، عملكرد 
تأثير درمان CDT به همراه آموزش برنامه خانكى ماساز، ورزش و مراقبت از يوست در بيماران مبتلا به لنف ادم ادمان

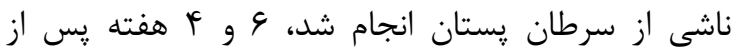

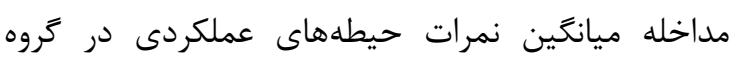
مداخله بهبود قابل توجهى نسبت به كرئه

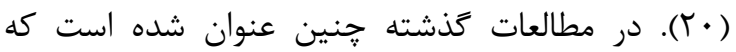

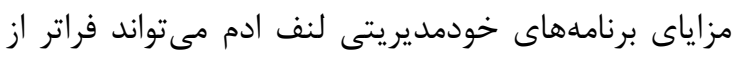

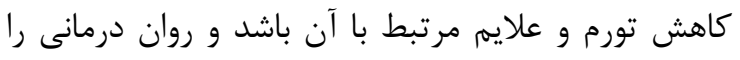

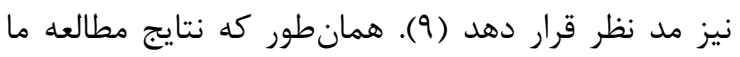

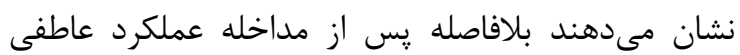

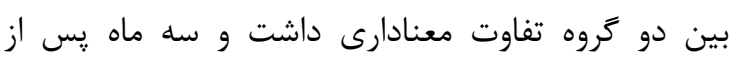

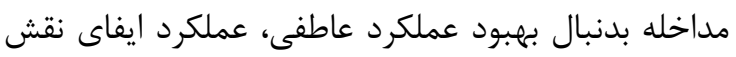

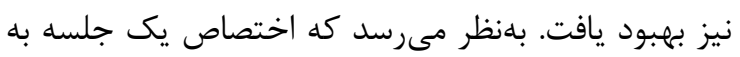

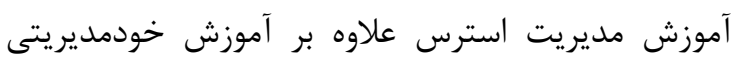
جنين نتيجهاى را دربرداشته است. از آنجا كه نمونه إنهاى

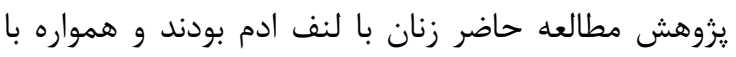

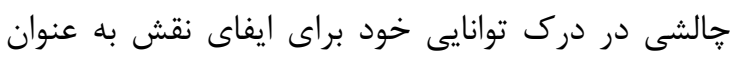

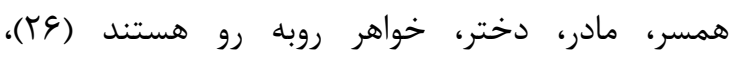

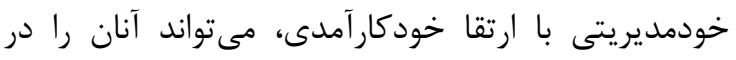

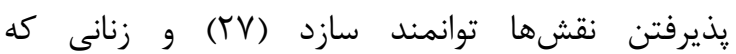
خودكارآمدى خود در كنترل لنف ادم و عوارض همراه آن آن

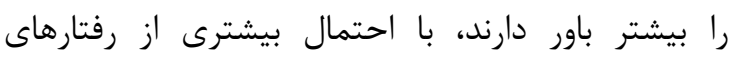

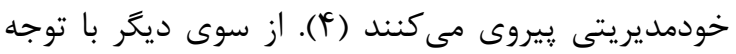

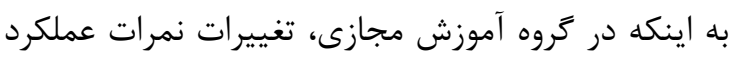

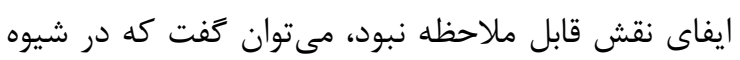

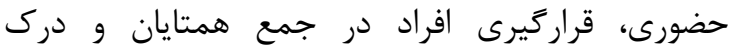

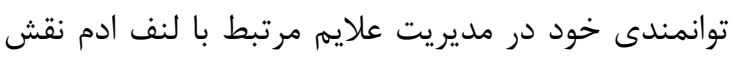

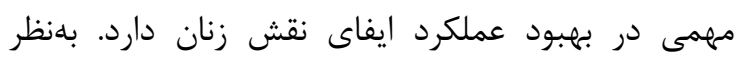

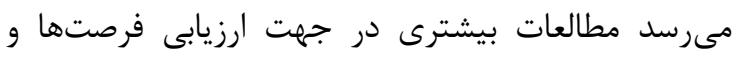

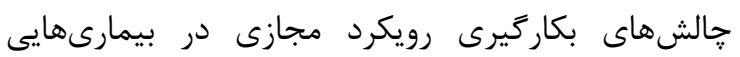
همجون لنف ادم نياز است. بهدنبال آموزش حضورى ميانه نمرات تصوير بدنى از لناز r r

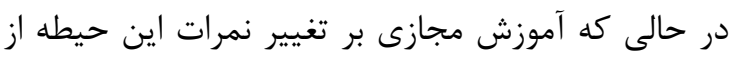

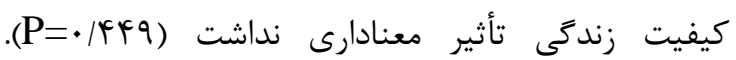
بدشكلى يا ناهنجارى در اندام منجر به از بين رفتن اعتماد

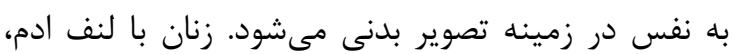

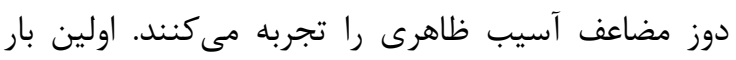
بدشكلى به دنبال جراحى و در ادامه بدشكلى ناشى از لنف
نتايج مطالعه Arinaga و همكاران، اثربخشى برنامه خودمراقبتى كاهش حجم بازو در بيماران مبتلا به لنف ادم ادماني ناشى از سرطان يستان بر بهبود حجم بازوى مبتلا، علائم

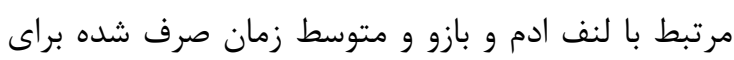

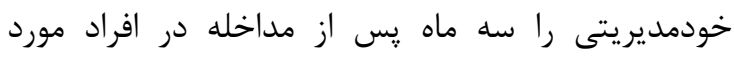

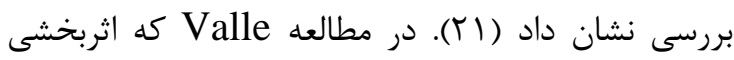

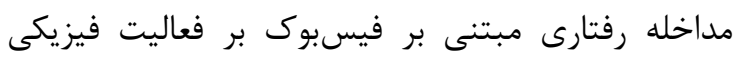

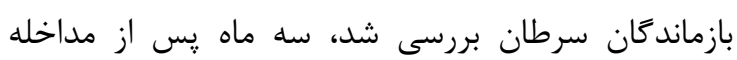

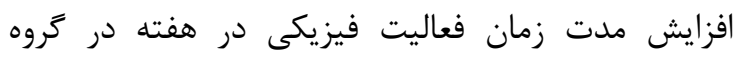

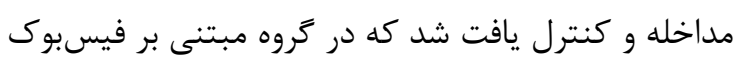

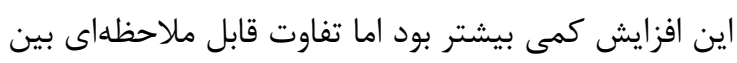

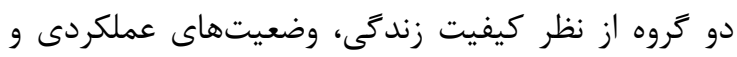

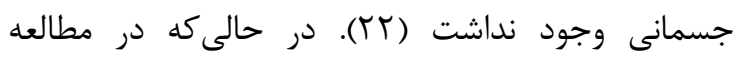

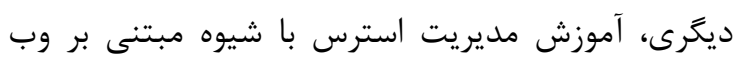

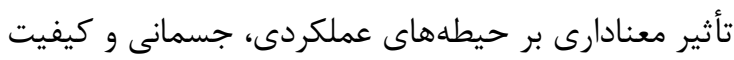

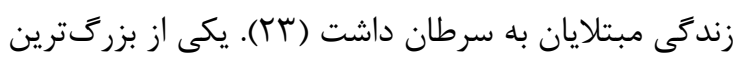

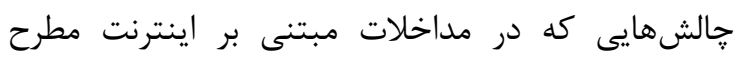

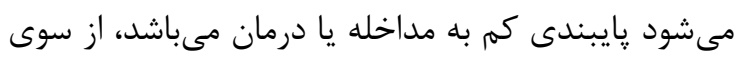

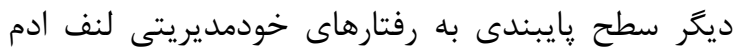

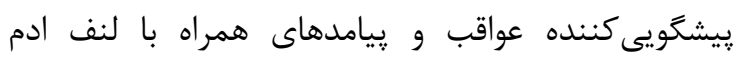

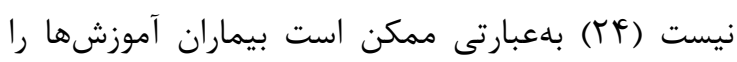

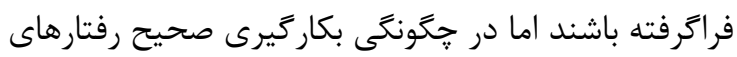
خودمديريتى دجار مشكل باشند. در مطالعه حاضر اين

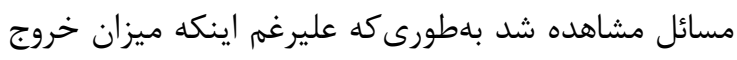

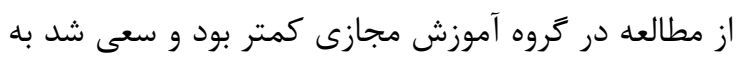

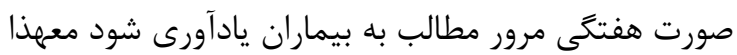

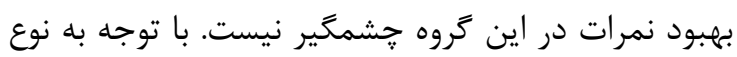

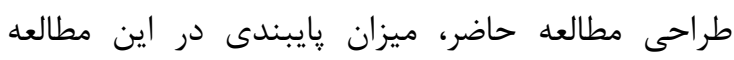

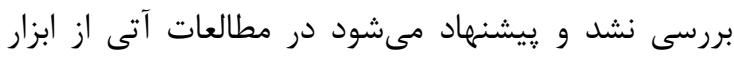

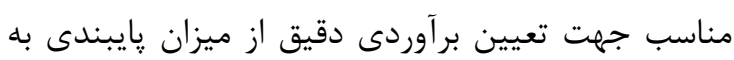
رفتارهاى خودمديريتى استفاده شود.

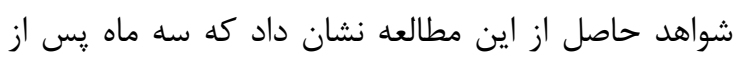

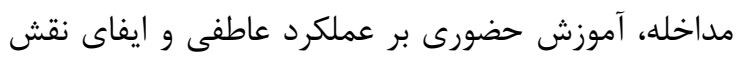

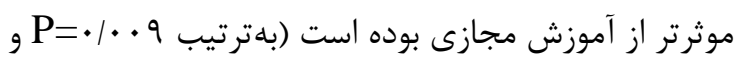

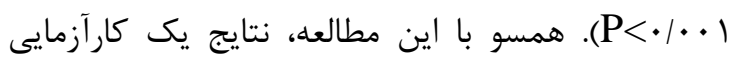

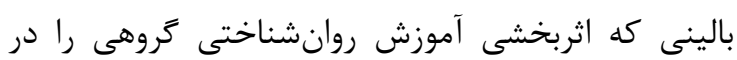

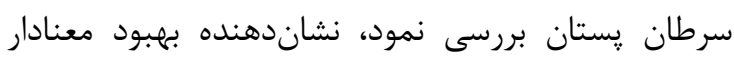

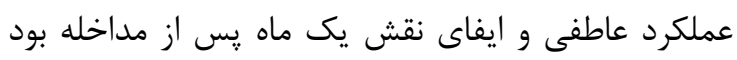

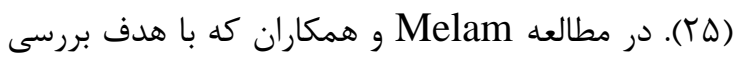


ارائه شد شايد بتوان يكى از دلايل تاثير كمتر آموزش

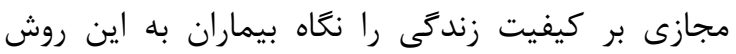

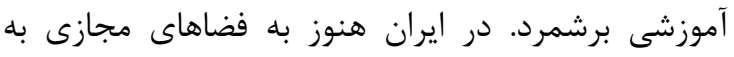

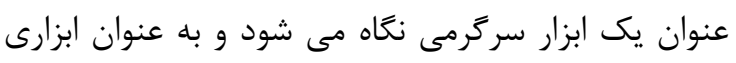

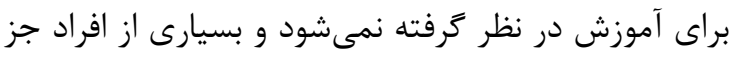

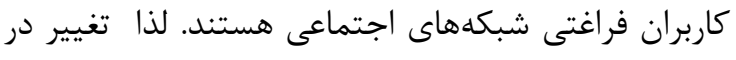

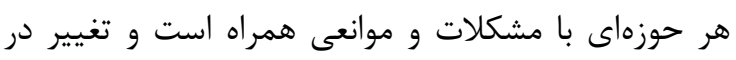

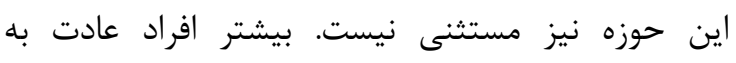

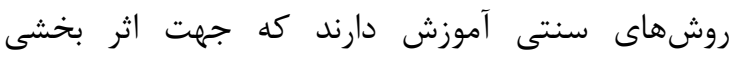

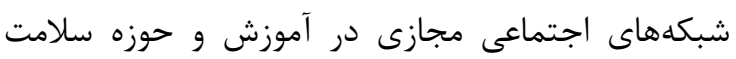
مطالعات بيشترى نياز مىباشد.

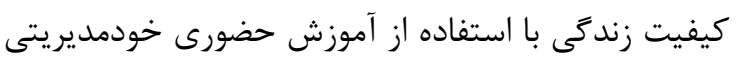

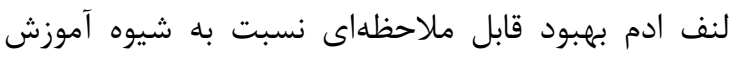

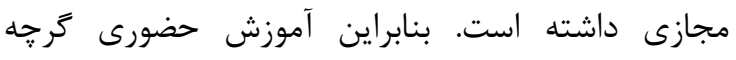

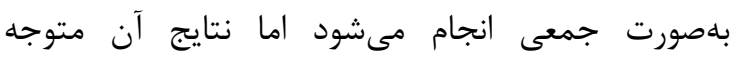

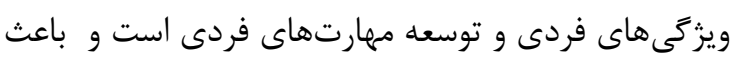

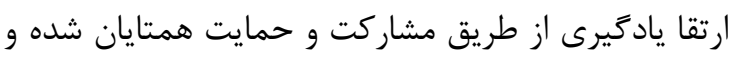

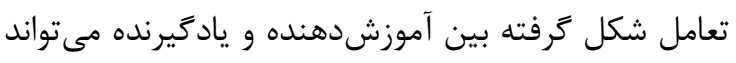

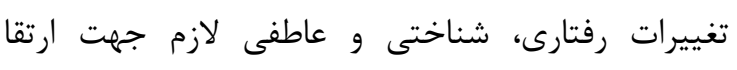

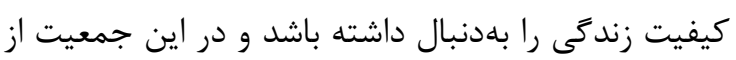

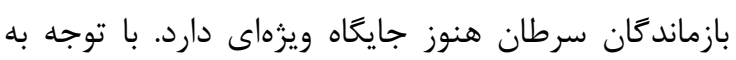

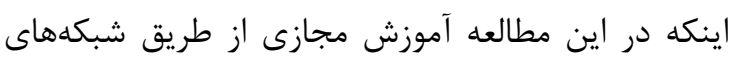

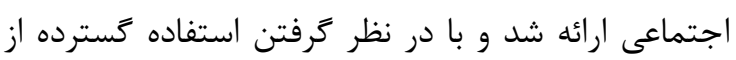

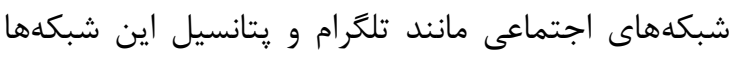

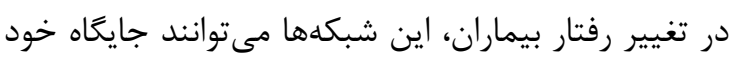

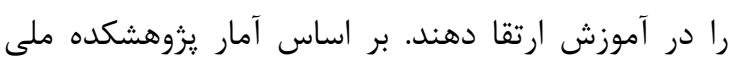

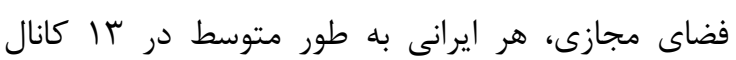

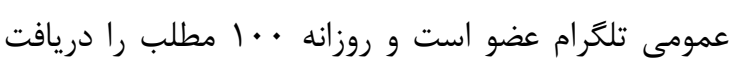

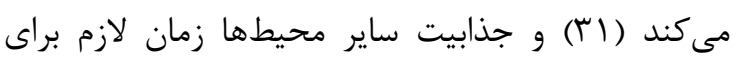

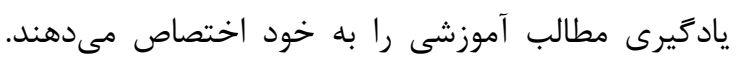

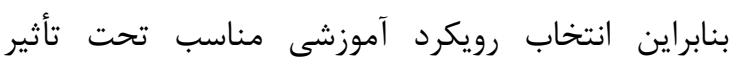

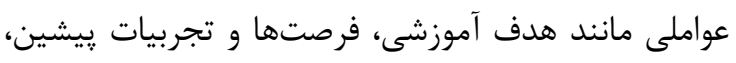

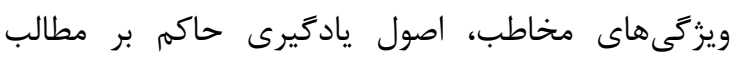

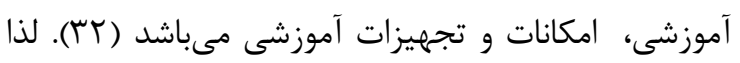

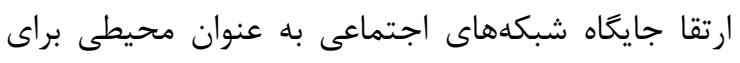

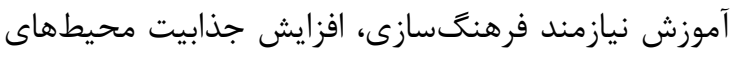

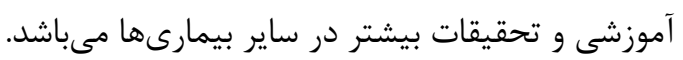

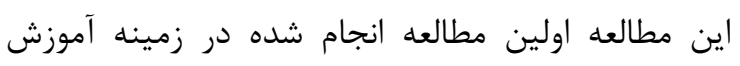

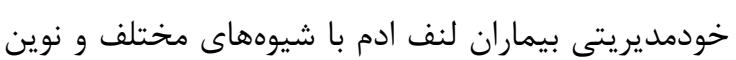

ادم. جون لنف ادم مىتواند سالها يس از درمان سرطان

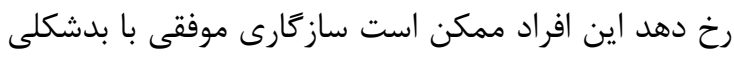

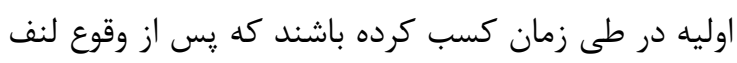

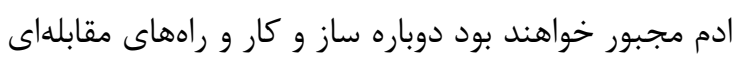

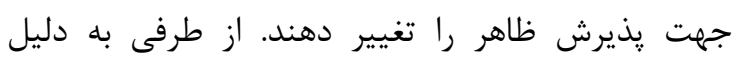

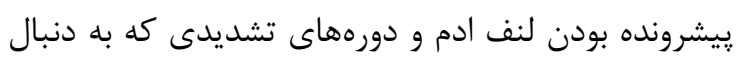

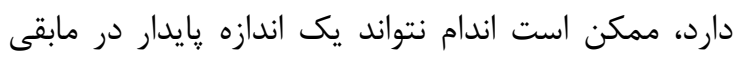

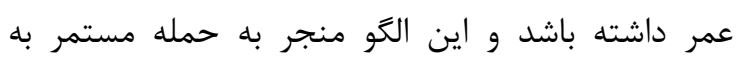

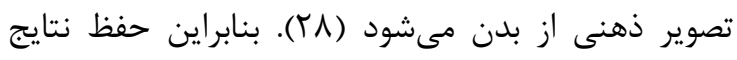

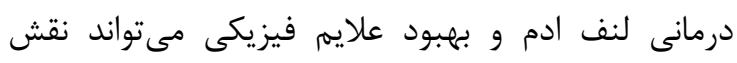

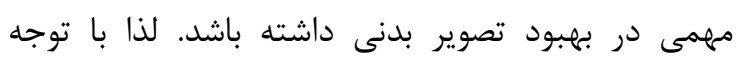

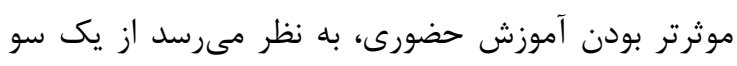

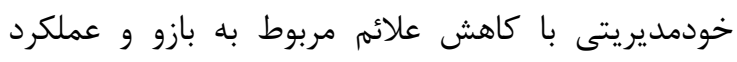

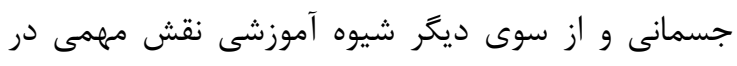

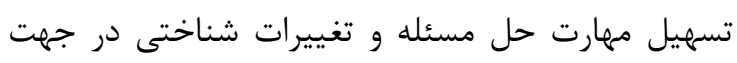

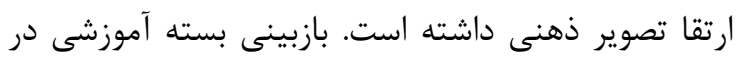

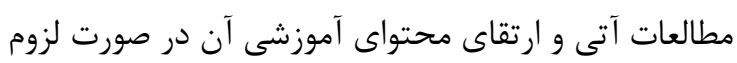

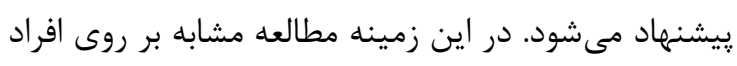

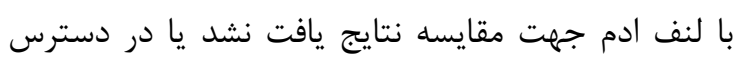
محقق قرار نترفت. بر اساس شواهد حاصل از اين يزوهش، نرف در روند مطالعه نمره سلامت عمومى در كروه حضورى از

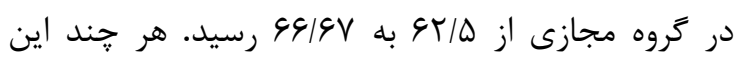

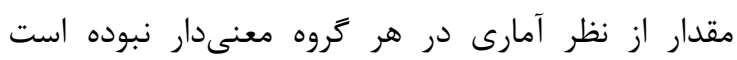

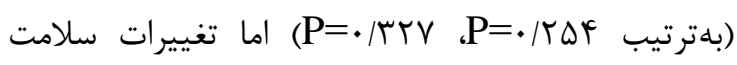

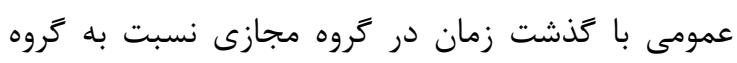

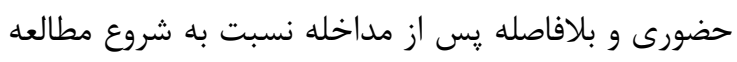

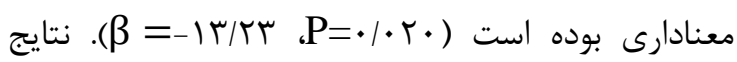

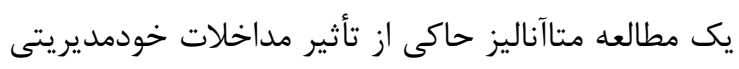

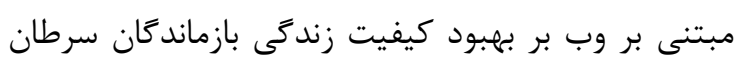

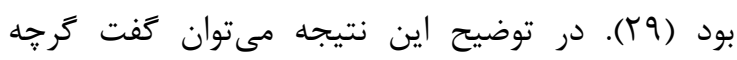

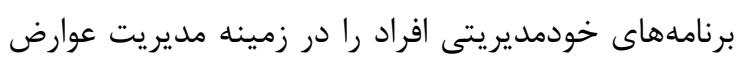

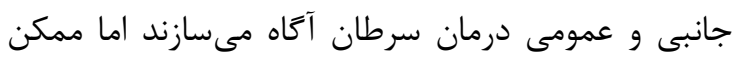

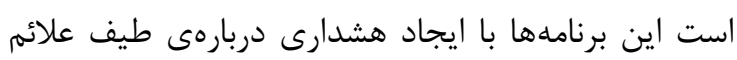

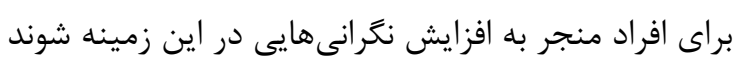

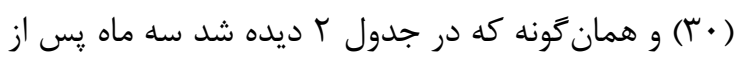

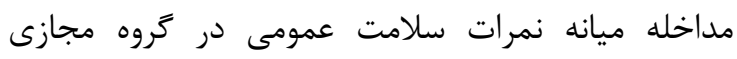

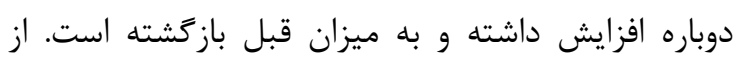

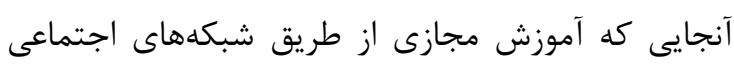


مختلف آموزشى در جهت بهبود كيفيت زندكَى، نتايج درمانى و كاهش عود لنف ادم استفاده نمايند اما بهنظر مىرسد مىبايست هزينه اثربخشى و بررسى بيشتر اين روشهاى آموزشى در مطالعات آينده مورد بررسى قرار كيرد تا منجر به انتخاب شيوه مناسب آموزشى شود.

\section{تشكر و قدردانى}

اين تحقيق بركرفته از پاياننامه مقطع كارشناسىارشد مامايى مىباشد كه توسط كمك هزينه تحقيقاتى ترئى

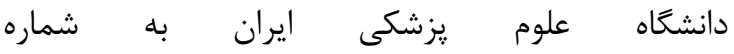
(IR.IUMS.REC1395.9411173002)

شد. نويسنده از معاونت يزوهشى و تحصيلات تكميلى دانشكده يرستارى مامايى دانشعاه علوم يزشكى ايران، تمامى زنان شركت كننده در مطالعه و كليه : يرسنل كلينيك لنف ترايى سيدخندان كمال تشكر را دارد.

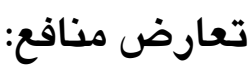

نويسندگان اعلام مى دارند كه هيجگَّنه تعارض منافعى در يزوهش حاضر وجود ندارد.

\section{References}

1. Wanchai A, Armer JM, Stewart BR, Lasinski BB. Breast cancer-related lymphedema: A literature review for clinical practice. International Journal of Nursing Sciences. 2016; 3(2):202-7.

2. Ridner SH, Dietrich MS, Kidd N. Breast cancer treatment-related lymphedema selfcare: education, practices, symptoms, and quality of life. Supportive care in cancer : official journal of the Multinational Association of Supportive Care in Cancer. 2011; 19(5): 631-7.

3. Borman P, Yaman A, Yasrebi S, Özdemir O. The Importance of Awareness and Education in Patients with Breast Cancer-Related Lymphedema. Journal of Cancer Education. 2016; 32(3):629-33.

4. Alcorso J, Sherman KA, Koelmeyer L, Mackie H, Boyages J. Psychosocial factors associated with adherence for selfmanagement behaviors in women with breast

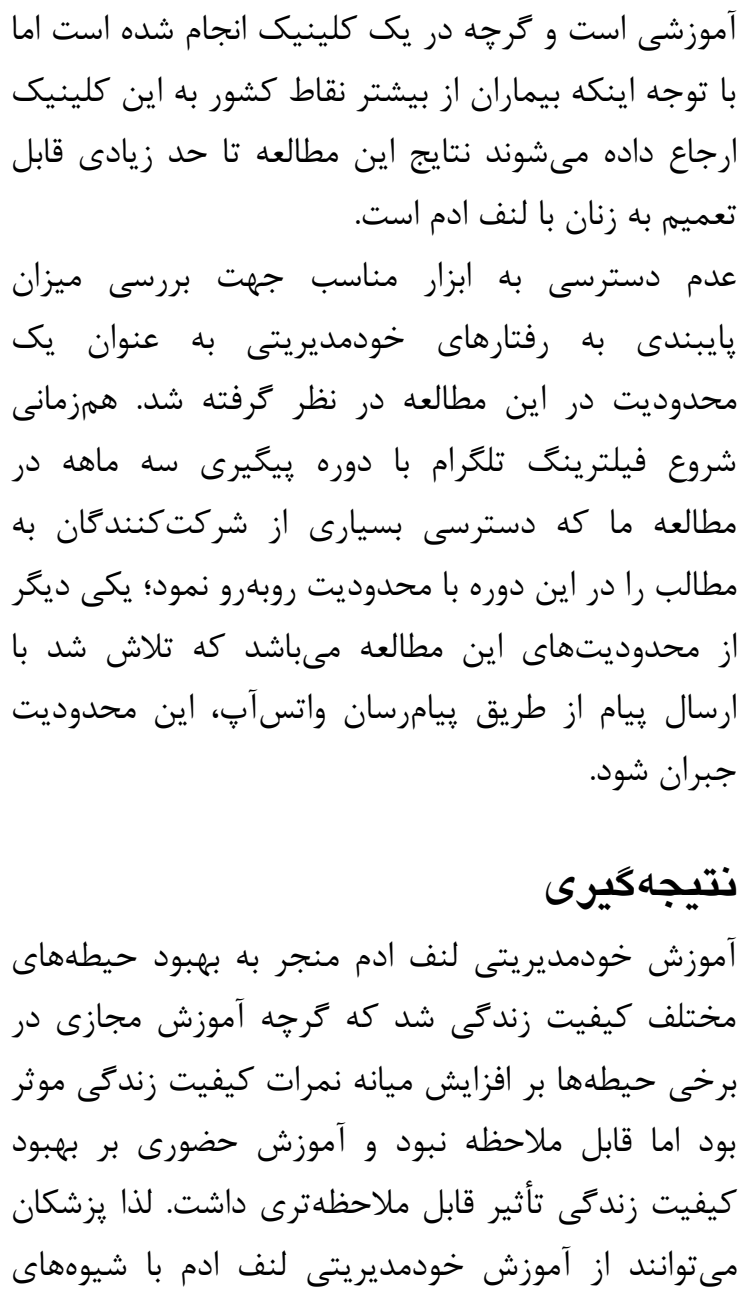

آموزش خودمديريتى لنف ادم منجر به بهبود حيطههاى

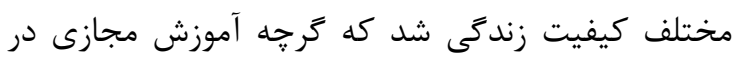
برخى حيطهها بر افزايش ميانه نمرات كيفيت زندگى موثر بود اما قابل ملاحظه نبود و آموزش حضورى بر بهبود مبرد

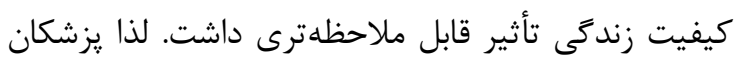
مىتوانند از آموزش خودمديريتى لنف ادم با شيوههاى

cancer-related lymphedema. Supportive Care in Cancer. 2016; 24(1):139-46.

5. Ahmed RL, Prizment A, Lazovich D, Schmitz KH, Folsom AR. Lymphedema and quality of life in breast cancer survivors: the Iowa Women's Health Study. Journal of clinical oncology: official journal of the American Society of Clinical Oncology. 2008; 26(35): 5689-96.

6. Taghian NR, Miller CL, Jammallo LS, O'Toole J, Skolny MN. Lymphedema following breast cancer treatment and impact on quality of life: a review. Critical reviews in oncology/hematology. 2014; 92(3): 227-34.

7. Pusic AL, Cemal Y, Albornoz C, Klassen A, Cano S, Sulimanoff I, et al. Quality of life among breast cancer patients with lymphedema: a systematic review of patientreported outcome instruments and outcomes. Journal of Cancer Survivorship. 2013; 7(1): 83-92. 
8. Faett BL, Brienza DM, Geyer MJ, Hoffman LA. Teaching Self-Management Skills in Persons with Chronic Lower Limb Swelling and Limited Mobility: Evidence for Usability of Telerehabilitation. International journal of telerehabilitation. 2013; 5(1):17.

9. Ridner SH, Fu MR, Wanchai A, Stewart BR, Armer JM, Cormier JN. Self-management of lymphedema: a systematic review of the literature from 2004 to 2011. Nursing research. 2012; 61(4): 291-9.

10. Rissanen R, Arving C, Ahlgren J, Nordin K. Group versus individual stress management intervention in breast cancer patients for fatigue and emotional reactivity: a randomised intervention study. Acta Oncologica. 2014; 53(9): 1221-9.

11. De Jongh T, Gurol-Urganci I, VodopivecJamsek V, Car J, Atun R. Mobile phone messaging for facilitating self-management of long-term illnesses. Cochrane Database of Systematic Reviews. 2012; 12.

12. Jansen F, van Uden-Kraan CF, van Zwieten V, Witte BI, Verdonck-de Leeuw IM. Cancer survivors' perceived need for supportive care and their attitude towards self-management and eHealth. Supportive Care in Cancer. 2015; 23(6): 1679-88.

13. Mohammadzadeh Z, Davoodi S, Ghazisaeidi M. Online Social Networks-Opportunities for Empowering Cancer Patients. Asian Pacific journal of cancer prevention: APJCP. 2015; 17(3): 933-6.

14. Balatsoukas P, Kennedy CM, Buchan I, Powell J, Ainsworth J. The Role of Social Network Technologies in Online Health Promotion: A Narrative Review of Theoretical and Empirical Factors Influencing Intervention Effectiveness. Journal of medical Internet research. 2015; 17(6):e141.

15. Laranjo L, Arguel A, Neves AL, Gallagher AM, Kaplan R, Mortimer $\mathrm{N}$, et al. The influence of social networking sites on health behavior change: a systematic review and meta-analysis. Journal of the American Medical Informatics Association: JAMIA. 2015; 22(1):243-56.

16. Fu MR, Axelrod D, Guth AA, Rampertaap K, El-Shammaa N, Hiotis K, et al. mHealth selfcare interventions: managing symptoms following breast cancer treatment. mHealth. 2016; 2 .

17. Montazeri A, Harirchi I, Vahdani M, Khaleghi F, Jarvandi S, Ebrahimi $M$, et al. The European Organization for Research and Treatment of Cancer Quality of Life Questionnaire (EORTC QLQ-C30): translation and validation study of the Iranian version. Supportive care in cancer : official journal of the Multinational Association of Supportive Care in Cancer. 1999; 7(6):400-6.

18. Montazeri A, Harirchi I, Vahdani M, Khaleghi F, Jarvandi S, Ebrahimi M, et al. The EORTC breast cancer- specific quality of life questionnaire (EORTC QLQ- BR23): translation and validation study of the Iranian version. Quality of life research : an international journal of quality of life aspects of treatment, care and rehabilitation. 2000; 9(2):177-84.

19. Ghavam-Nasiri M-R, Heshmati Nabavi F, Anvari K, Habashi Zadeh A, Moradi M, Neghabi G, et al. The Effect of Individual and Group Self-care Education on Quality of Life in Patients Receiving Chemotherapy: A Randomized Clinical Trial. Iranian Journal of Medical Education. 2012; 11(8):874-84.

20. Valle CG, Tate DF, Mayer DK, Allicock M, Cai J. A randomized trial of a Facebook-based physical activity intervention for young adult cancer survivors. Journal of Cancer Survivorship. 2013; 7(3):355-68.

21. Borman P, Yaman A, Yasrebi S, Özdemir O. The importance of awareness and education in patients with breast cancer-related lymphedema. Journal of Cancer Education. 2017; 32(3):629-33.

22. Melam GR, Buragadda S, Alhusaini AA, Arora N. Effect of complete decongestive therapy and home program on health-related quality of life in post mastectomy lymphedema patients. BMC women's health. 2016; 16(1):23.

23. Arinaga Y, Sato F, Piller N, Kakamu T, Kikuchi K, Ohtake T, et al. A 10 Minute SelfCare Program May Reduce Breast CancerRelated Lymphedema: A Six-Month Prospective Longitudinal Comparative Study. Lymphology. 2016; 49(2):93-106.

24. Urech C, Grossert A, Alder J, Scherer S, Handschin B, Kasenda B, et al. Web-Based Stress Management for Newly Diagnosed Patients With Cancer (STREAM): A Randomized, Wait-List Controlled Intervention Study. Journal of clinical oncology : official journal of the American Society of Clinical Oncology. 2018; 36(8): 780-96.

25. Brown JC, Kumar A, Cheville AL, Tchou JC, Troxel AB, Harris SR, et al. Association between lymphedema self-care adherence and lymphedema outcomes among women with breast cancer-related lymphedema. American journal of physical medicine \& rehabilitation/Association of Academic Physiatrists. 2015; 94(4):288. 
26. Dolbeault S, Cayrou S, Bredart A, Viala AL, Desclaux B, Saltel P, et al. The effectiveness of a psycho-educational group after earlystage breast cancer treatment: results of a randomized French study. Psycho-oncology. 2009; 18(6): 647-56.

27. Boogaard L, Gater L, Mori M, Trincao A, Smith-Turchyn J. Efficacy of Selfmanagement Programs in Managing Side Effects of Breast Cancer: A Systematic Review and Meta-analysis of Randomized Control Trials. Rehabilitation Oncology. 2016; 34(1):14-26.

28. Lorig KR, Holman HR. Self-management education: history, definition, outcomes, and mechanisms. Annals of behavioral medicine. 2003; 26(1):1-7.

29. Rhoten BA, Radina ME, Adair M, Sinclair V, Ridner SH. Hide and seek: Body imagerelated issues for breast cancer survivors with lymphedema. Journal of Womens Health, Issues and Care. 2016; 4(2):2-7.
30. Kim AR, Park HA. Web-based Selfmanagement Support Interventions for Cancer Survivors: A Systematic Review and Metaanalyses. Studies in health technology and informatics. 2015; 216:142-7.

31. Smith-Turchyn J, Morgan A, Richardson J. The Effectiveness of Group-based Selfmanagement Programmes to Improve Physical and Psychological Outcomes in Patients with Cancer: a Systematic Review and Metaanalysis of Randomised Controlled Trials. Clinical oncology. 2016; 28(5): 292-305.

32. National Center for Cyberspace. The activity eleven thousand and ten channel of Telegram with more than fifty thousand members 2016 [cited 2018 11Oct]. Available from: http://www.majazi.ir/news.

33. Asgari P, Bahramnezhad F, Shiri M, Fathi A, Afsharipour G. The Effect of Group Training and E-learning on Self -Perception in Diabetes Adolescents \% J Iran Journal of Nursing. Iran Journal of Nursing. 2016; 29(103): 33-40. 